\title{
One rate does not fit all: An empirical analysis of electricity tariffs for residential microgrids
}

\author{
Gilbert Fridgen $^{\mathrm{a}}$, Micha Kahlen ${ }^{\mathrm{b}}$, Wolfgang Ketter ${ }^{\mathrm{c}, \mathrm{b}}$, Alexander Rieger ${ }^{\mathrm{a}, *}$, Markus Thimmel ${ }^{\mathrm{a}}$ \\ ${ }^{\text {a } F I M ~ R e s e a r c h ~ C e n t e r, ~ U n i v e r s i t y ~ o f ~ B a y r e u t h, ~ W i t t e l s b a c h e r r i n g ~ 10, ~} 95444$ Bayreuth, Germany \\ b Rotterdam School of Management, Erasmus University, Burgemeester Oudlaan 50, 3062 PA Rotterdam, The Netherlands \\ ${ }^{c}$ Institute of Energy Economics at the University of Cologne, University of Cologne, Alte Wagenfabrik - Vogelsanger Str. 321 , 50827 Cologne, Germany
}

\section{H I G H L I G H T S}

- We empirically analyze twelve electricity tariffs for residential microgrids.

- We calculate that tariffs with volumetric rates would encourage grid destabilization.

- We show that capacity charges would moderate the impact of time-varying rates.

- We find that a mix of capacity and customer charges would benefit all stakeholders.

\section{A R T I C L E I N F O}

\section{Keywords:}

Capacity charges

Electricity tariffs

Residential microgrids

Simulation

Smart electricity markets

Time-varying rates

\begin{abstract}
A B S T R A C T
Increasingly, residential customers are deploying PV units to lower electricity bills and contribute to a more sustainable use of resources. This selective decentralization of power generation, however, creates significant challenges, because current transmission and distribution grids were designed for centralized power generation and unidirectional flows. Restructuring residential neighborhoods as residential microgrids might solve these problems to an extent, but energy retailers and system operators have yet to identify ways of fitting residential microgrids into the energy value chain. One promising way of doing so is the tailoring of residential microgrid tariffs, as this encourages grid-stabilizing behavior and fairly re-distributes the associated costs. We thus identify a set of twelve tariff candidates and estimate their probable effects on energy bills as well as load and generation profiles. Specifically, we model 100 residential microgrids and simulate how these microgrids might respond to each of the twelve tariffs. Our analyses reveal three important insights. Number one: volumetric tariffs would not only inflate electricity bills but also encourage sharp load and generation peaks, while failing to reliably allocate system costs. Number two: under tariffs with capacity charges, time-varying rates would have little impact on both electricity bills and load and generation peaks. Number three: tariffs that bill system and energy retailer costs via capacity and customer charges respectively would lower electricity bills, foster peak shaving, and facilitate stable cost allocation.
\end{abstract}

\section{Introduction}

The microgrid idea mirrors the first self-contained electric systems that existed prior to the advent of utilities [1]. Conceptually, microgrids are interconnected clusters of DG units, electrical loads, and storage units, that can operate both in connection (grid-connected mode) and independent (islanded mode) of the larger macrogrid [2]. They facilitate distributed optimization of electricity networks and can improve system reliability, sustainability, and cost-efficiency [3-5]. To date, they have not been widely implemented, yet numerous successful pilots indicate technical feasibility [5-8]. Considerable efforts are still required, however, to integrate microgrids into the energy value chain and to define viable business models [7]. This integration is especially challenging in deregulated energy markets where microgrid operators, energy retailers, and system operators are different entities with diverging economic objectives. Whereas microgrid operators ${ }^{1}$ effectively aim to secure their energy needs at the lowest possible cost [9], distribution system operators (DSOs) and transmission system operators

\footnotetext{
* Corresponding author.

E-mail addresses: gilbert.fridgen@fim-rc.de (G. Fridgen), kahlen@rsm.nl (M. Kahlen), wketter@rsm.nl (W. Ketter), alexander.rieger@fim-rc.de (A. Rieger), markus.thimmel@fim-rc.de (M. Thimmel).

${ }^{1}$ We expect that most future residential microgrids will be run by professional microgrid managers with specific know-how, well-trained staff, and sufficient capital.
} 


\section{Nomenclature \\ Indices and model size \\ h household index [-] \\ i appliance run index. An appliance run can be, for ex- ample, a single use of a washing machine or one cooling cycle of a refrigerator [-] period index [-] \\ $\mathrm{H} \quad$ total number of households [-] \\ I total number of appliance runs [-] \\ $\mathrm{T}$ total number of periods in the simulation [-]}

\section{Model variables}

bc overall capacity of all microgrid batteries. Continuous variable (non-negative) [kWh]

$c_{t}$ total energy used to charge the microgrid's batteries in period t. Continuous variable (non-negative) [kWh]

$d_{t} \quad$ total energy discharged from the microgrid's batteries in period t. Continuous variable (non-negative) [kWh]

$\mathrm{p} \quad$ maximum absolute peak over the simulation horizon: maximum amount of electricity that is exchanged with the grid in a single period. Continuous variable [kW]

$\mathrm{sgc}_{\mathrm{t}} \quad$ solar generation curtailment factor in period t. Continuous variable $\in[0,1][\mathrm{kWh}]$

$\mathrm{soc}_{\mathrm{t}} \quad$ total state of charge of all microgrid batteries in period $\mathrm{t}$. Continuous variable [kWh]

tc total electricity costs [USD]

$\mathrm{wgc}_{\mathrm{t}} \quad$ wind generation curtailment factor in period t. Continuous variable $\in[0,1][\mathrm{kWh}]$

$\mathrm{x}_{\mathrm{h}, \mathrm{i}, \mathrm{t}} \quad$ appliance run activity indicator. Binary variable; one if appliance run $i$ in household $h$ is active in period $t$ [-]

$\mathrm{y}_{\mathrm{h}, \mathrm{i}, \mathrm{t}} \quad$ prevents repetition of an already finished appliance run. Binary variable; one if appliance run $i$ in household $h$ is already finished in period $t[-]$

$z_{d_{t}} \quad$ difference between generation and usage if period $t$ is a period of surplus demand; to be weighted with the purchasing price. Continuous variable (non-negative) [kWh] difference between generation and usage if period $t$ is a period of surplus generation; to be weighted with the selling price. Continuous variable (non-negative) [kWh]
Parameters

$\mathrm{AH}_{\mathrm{h}, \mathrm{i}} \quad$ appliance run to household indicator. Binary variable; one if appliance run i belongs to household $\mathrm{h}[-]$

$\mathrm{BC}$ total capacity of the microgrid's batteries [kWh]

CapC capacity charge [USD/kW]

$\operatorname{CusC}_{\mathrm{x}} \quad$ customer charge in the respective non-volumetric pricing scenarios [USD]

$\mathrm{CPP}_{t} \quad$ critical peak price in period $t$. This price is only in effect during a system-wide peak period and is 0 in all other periods [USD/kWh]

$\mathrm{FL}_{\mathrm{t}} \quad$ fixed load in period t. Residual, non-shiftable loads [kWh]

$\mathrm{FPP}_{\mathrm{X}, \mathrm{X}} \quad$ flat purchasing price in the respective flat and critical peak pricing scenarios [USD $/ \mathrm{kWh}]$

FSP flat selling price [USD/kWh]

MCR maximum charging rate: physical limit of energy storable in all microgrid batteries in each period $\mathrm{t}$ [kWh]

MDR maximum discharging rate: physical limit of energy accessible from all microgrid batteries in each period $t$

[kWh]

$\mathrm{PC}_{\mathrm{i}} \quad$ energy consumed by each appliance run or electric vehicle charging process $[\mathrm{kWh}]$

$\mathrm{PT}_{\mathrm{i}} \quad$ processing time of each appliance run or electric vehicle charging process $[-]$

$\mathrm{RTPP}_{\mathrm{t}, \mathrm{x}}$ real-time purchasing price in period $\mathrm{t}$ in the respective real-time pricing scenarios [USD $/ \mathrm{kWh}$ ]

$\mathrm{RTSP}_{\mathrm{t}}$ real-time selling price in period t [USD $/ \mathrm{kWh}$ ]

RTE aggregated round-trip efficiency of the microgrid batteries [-]

$\mathrm{SGen}_{\mathrm{t}} \quad$ solar energy generated in period $\mathrm{t}[\mathrm{kWh}]$

$\mathrm{SoC}_{\text {init }} \quad$ total initial state of charge of all microgrid batteries [kWh]

$\mathrm{SoC}_{\text {min }}$ total minimum state-of-charge of all microgrid batteries to avoid undue degradation [kWh]

ToUPP $_{t, x}$ time-of-use purchasing price in period $t$ in the respective time-of-use pricing scenarios [USD/kWh]

ToUSP $_{t}$ time-of-use selling price in period $\mathrm{t}$ [USD/kWh]

$\mathrm{UP}_{\mathrm{i}, \mathrm{t}} \quad$ user preference indicator providing the permissible execution windows for appliances. A value of one states that appliance run $\mathrm{i}$ can be scheduled in period $\mathrm{t}[-]$

$\mathrm{VolC}_{\mathrm{x}, \mathrm{x}} \quad$ volumetric charge in the respective volumetric and partially volumetric pricing scenarios [USD/kWh]

$\mathrm{WGen}_{\mathrm{t}} \quad$ wind energy generated in period $\mathrm{t}[\mathrm{kWh}]$
(TSOs) seek to put a cap on the microgrid's peak loads and fully recover their grid infrastructure investments $[10,11]$. Similarly, energy retailers are concerned with full cost-recovery and stable load patterns to minimize costs for balancing power [12]. Reconciling all of these vested interests has certainly proven to be difficult $[13,14]$, yet there is reason to believe that tailored electricity tariffs might become the means of choice for linking all players in the microgrid value chain [15-18].

The key challenge to designing effective tariffs for residential microgrids is that common pricing mechanisms for residential customers might not be appropriate for residential microgrids. Feed-in tariff (FiT) mechanisms, for example, offer little incentive for local demand-supply balancing [19], while net metering enforces a single rate for energy purchases and sales [20]. Instead, most microgrid evaluation studies (implicitly) assume, that future policies will stipulate a net purchase and sale approach $[14,18,21-26]$. This mechanism has the same principal set-up as net metering, but it explicitly permits different prices for times of net load and net generation.

For instance, Speidel et al. [21] evaluate a time-of-use (ToU) tariff that charges for net load, yet does not remunerate net generation. They show that such a tariff could effectively encourage microgrid operators to manage their dependence on external power. In contrast, Atia et al.
[22] look at a ToU tariff that also prices net generation. They calculate that both the net generation rate and a sufficiently large range between the highest and the lowest ToU price would be crucial for economic microgrid operation. Several residential microgrid studies also examine demand charges, i.e., charges that price the highest net load peak over the billing period. Hanna et al. [18] and Zheng et al. [23], e.g., look at demand charges with seasonal variation. They estimate that these charges would encourage considerable peak leveling and result in sizeable economic benefits to microgrid operators. Li et al. [24] find similar effects for ToU demand charges that apply only to certain periods, as do Zhang et al. [25] for excess demand charges that apply only to net loads beyond a certain threshold. Ultimately, Sreedharan et al. [26] estimate that demand charges could also encourage microgrid operators to increase self-supply from non-intermittent generation. Meanwhile, Rieger et al. [14] evaluate so-called capacity charges: unlike demand charges, which only price net load peaks, these charges apply to the highest absolute net generation or net load peak. Hence, the authors argue these capacity charges better reflect that residential microgrids can act both as consumers and producers and find them to be highly effective in stabilizing load and generation profiles.

What these studies show is that electricity tariffs can have 
considerable effects. They do not, however, attempt to systematically review tariff design options beyond one or two selected tariffs. Firestone et al. [27], on the other hand, take an important initial step in this direction by empirically evaluating how different tariffs would influence a microgrid operator's decision to install distributed generation. Unfortunately, these tariffs do not stipulate remuneration for net generation and the authors only provide results for a single hospital. A more recent study by Schreiber et al. [28] also reviews several tariff options for residential microgrids, yet the evaluated tariffs all share the same basic design and price net generation at a constant flat rate.

Consequently, our study's principal objective is to take this analysis a step further by systematically reviewing tariff options for residential microgrids. To this end, we singled out the most common tariff elements for commercial, residential, and DG-backed customers, which we then combined into twelve potential net purchase and sale tariffs. These tariffs differ in two regards: how dynamically they price power (flat, time-of-use, critical peak, and real time) and how they charge the microgrid for distribution and transmission costs as well as energy retailer service (based on volumetric, capacity, and customer charges). Importantly, they reflect two key challenges in designing effective tariffs for residential microgrids. Number one, future tariffs should reflect that residential microgrids can systematically alternate between demanding and supplying power from and to the macrogrid. Number two, residential microgrid tariffs should minimize incentives to discard excess power or game the system. These tariffs therefore include capacity charges rather than demand charges and price power, i.e., both net generation and net load, at the same (time-varying) rate.

To compare their effects on load profiles and their economic potential, we analyzed these twelve tariffs with an empirical evaluation framework. Conceptually, this framework starts by building an artificial residential microgrid from real-world load and distributed generation data. It then simulates how the microgrid operator would minimize its overall electricity costs by scheduling smart loads, deciding on battery charging trajectories, and curtailing distributed generation.

To instantiate the evaluation framework, we primarily leveraged data from the Pecan Street Dataport [29], which provides per-appliance power demand and residential photovoltaic (PV) generation measurements (down to a $15 \mathrm{~s}$ level) for more than 1,300 households in the US. Of these, we selected 263 homes located in Austin, Texas which had complete hourly data for their installed appliances, electric vehicles (EVs), and PV units in 2015. To supplement this data, we used the power curve of a Fortis Alizé type small wind turbine by Fortis Wind B.V. [30] to translate Austin wind speeds into wind power output. We also factored in battery storage by replicating the technical parameters of the Powerwall 2 home battery by Tesla, Inc. [31].

The intended purpose of this paper is to inform energy retailers, DSOs, and TSOs on the probable effects of different tariff designs. Furthermore, it is our hope that microgrid investors will likewise reflect our results in the planning process of future microgrid projects. Our tariff designs can easily be integrated, for example, with the Hybrid Optimization of Multiple Energy Resources (HOMER) model or the Distributed Energy Resources Customer Adoption Model (DER-CAM), two popular solutions for microgrid planning [32].

The remainder of this paper is structured as indicated in Fig. 1. Section 2 introduces the selected twelve tariffs and their characteristics. Section 3 describes our evaluation framework, its residential microgrid model, and the mixed integer linear program (MILP) that the framework uses to balance loads and generation. In Section 4, we discuss our input data and the adjustments required to fit them into our framework. Section 5 presents our simulation results and translates these into tariff design recommendations. Section 6 closes with a summary of our study's key results and a review of its limitations.

\section{Electricity tariffs under consideration}

Although many countries in Europe, North America, and Asia have joined efforts to promote green distributed generation, there is little consensus on the ideal pricing mechanism for residential customers with DG, let alone residential microgrids. For instance, feed-in tariffs are popular in Europe. Many US states apply net metering. Meanwhile,
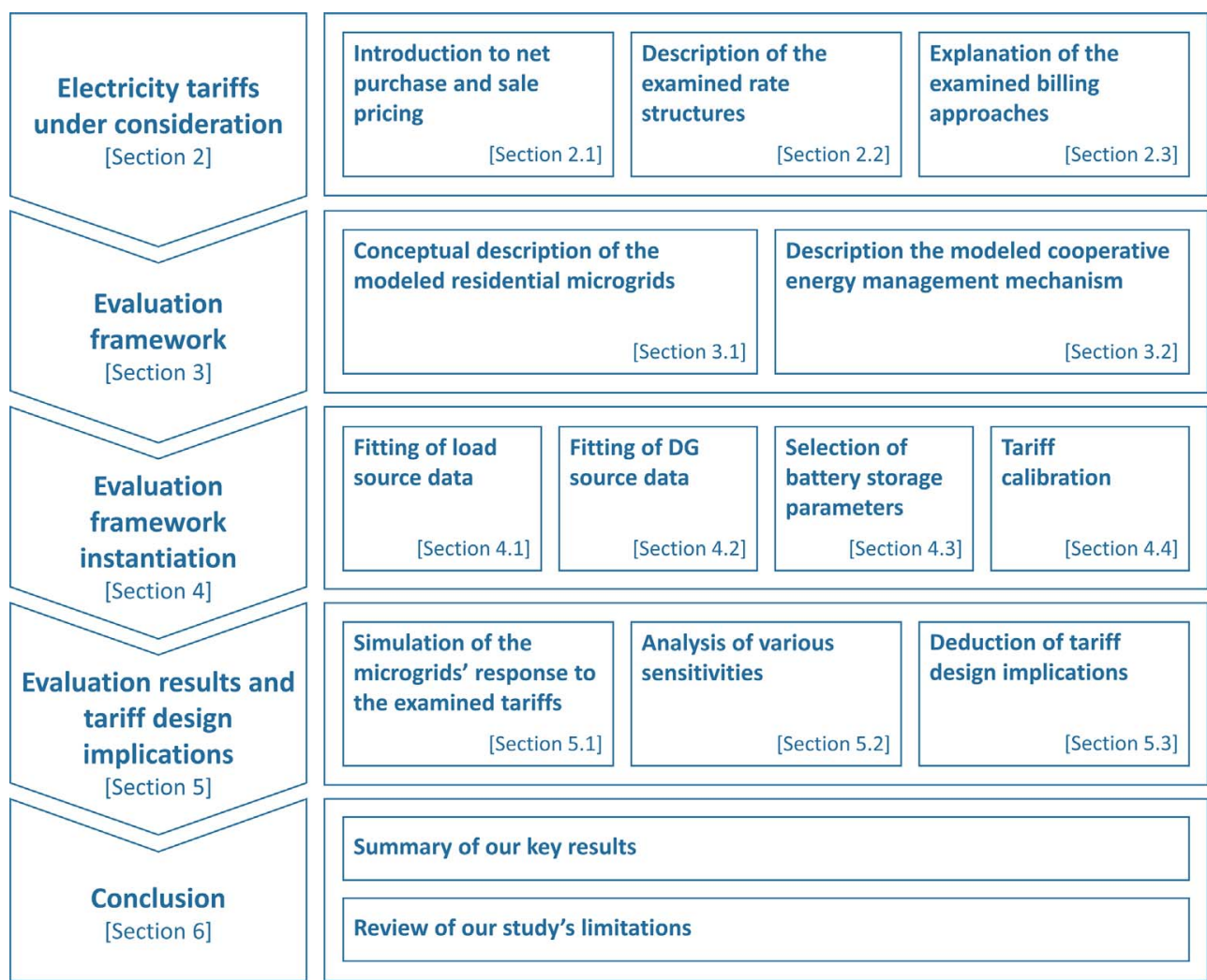

Fig. 1. Schematic overview of our tariff evaluation study. 
Japan has opted for a net purchase and sale approach [33]. While each of these alternatives has pros and cons, the deciding factor in implementing them is the level of control policy-makers want to exert. Feed-in tariffs, for example, allow policy-makers to set individual development trajectories for each power source. However, these feed-in rates are risky and can result in non-negligible cross-subsidies from customers without DG to those with DG if policy-makers do not 'get them right' [34]. Net metering mechanisms in turn allow less control as they simply pay the local residential rate for each form of distributed generation $[20,35]$. Net purchase and sale approaches, on the other hand, promote far-reaching self-regulation as they neither stipulate a regulated DG rate (as with feed-in tariffs), nor lock in high residential rates (as with net metering) [36].

Net purchase and sale, also known as net billing, employs two separate meters to independently track net distributed generation and net load $[33,36]$. As indicated in Fig. 2, these two meters record the customer's precise energy flows and thus allow energy retailers to account for net generation and net load separately, dynamically, and at different prices. This policy is especially interesting for residential microgrids as these (a) represent a single aggregate unit of loads and distributed generation and (b) systematically alternate between periods of net generation and net load. Hence, most microgrid evaluation studies (implicitly) stipulate net purchase and sale pricing [14,18,21-26].

Although net purchase and sale pricing allows various tariff options for residential microgrids, certain practical considerations limit this pricing flexibility. Tariffs that do not price net generation, for example, are not economically efficient and encourage downsizing of DG units $[22,27]$. Moreover, selling prices should also not exceed wholesale market levels to avoid cross-subsidies [37]. Similarly, we suggest not to vary pricing for net load and net distributed generation. Although doing so might be beneficial in specific scenarios, it logically breeds asymmetric risk positions that benefit either energy retailers or microgrid operators [12].

Based on these considerations, we selected twelve potential net purchase and sale tariffs for our evaluation. As indicated in Fig. 3, we examined four common electricity rate structures and three options to bill residential microgrid operators for system (distribution and transmission) and energy retailer services.

\subsection{Examined electricity rate structures}

Over the last century, energy retailers have developed various approaches to billing customers for power generation and supply. Of these electricity rate structures, we included the four most prominent in our analysis: flat and time-of-use pricing (two static alternatives), as well as critical peak and real-time pricing (two dynamic options).

One: flat pricing. Here, the energy retailer offers a simple time-invariant rate for energy purchases (net load) and energy sales (net distributed generation). This approach closely mirrors current residential practice where customers pay a pre-set rate for each delivered $\mathrm{kWh}$, irrespective of the time of usage. Two: time-of-use pricing. In this case, the electricity rate varies with the time of day. Typically, time-of-use schemes include a low off-peak rate that applies during night hours, a higher shoulder rate for morning hours, and a peak rate during the afternoon and early evening [38]. Like the flat-rate structure, these rates are fixed contractually, i.e., energy retailers cannot adjust them dynamically. Three: critical peak pricing. This combines a simple and time-invariant flat rate with an energy retailer option to switch to an elevated rate during so-called peak events. These can be periods of threatened macrogrid stability or high wholesale market prices. In practice, energy retailers may call peak periods for a certain number of hours each year; however, they have to notify their customers up to a day ahead of the upcoming peak pricing schedule [39]. And lastly, four: real-time pricing. This option implements fully dynamic rates that track wholesale market prices [38]. Accordingly, they differ from hour to hour and from day to day.

\subsection{Billing for system and energy retailer services}

As with power generation, the electric power industry also developed particular options to charge customers for transmission and distribution as well as energy retailer services. For our analysis, we adapted the most common alternatives for residential, commercial, and DG customers.

Our first option is based on current residential practice where customers pay a single and aggregate volumetric (USD/kWh) charge for each kWh of electricity delivered to them. We call this approach fully volumetric. We inferred the second option, termed partially volumetric, from common pricing practices for commercial and industrial customers. These customers generally pay both volumetric (USD/kWh) charges and a demand (USD/kW) charge on the highest peak load during the billing period [37]. Our partially volumetric tariffs work on the basis of this two-part approach: they feature a volumetric charge for energy retailer services and a capacity charge for system costs. This capacity charge extends the demand charge concept by factoring in both demand and generation peaks, and it applies to the highest absolute (generation or load) peak. Our third charging option (non-volumetric) is inspired by Consolidated Edison's standby tariff for customers with distributed generation, which only stipulates customer (fixed US dollar) and demand charges [40]. The non-volumetric tariffs mirror this idea and employ a customer and a capacity charge for energy retailer and system services respectively.

\section{Evaluation framework}

Prior studies on residential tariff design have taken various evaluation approaches, from generic analytical models [19] to complex empirical evaluations with the prominent Distributed Energy Resources Customer Adoption Model (DER-CAM) [27]. Conversely, our study builds on an empirical framework by Rieger et al. [14], which offers a good tradeoff between computational overhead, flexibility, and evaluation robustness. This framework has two key components: a simplified representation of the structure and behavior of a residential microgrid, and a detailed mixed integer linear programming (MILP) mechanism, which simulates cooperative energy management.

We made three adjustments to this framework to improve its applicability as well as its functionality. Number one, we extended the residential microgrid model by adding a new element for community wind energy and equipped all homes that own PV units with residential battery storage. Number two, we extended the simulation engine with six new constraints for battery storage management and enabled distributed generation curtailment, i.e., the mechanism could curtail distributed generation if this was cost-effective. Number three, we generalized the objective function to accommodate each of the twelve tariffs examined. Details about these adjustments and explanations about our residential microgrid model are provided below.

\subsection{Residential microgrid model}

As illustrated in Fig. 4, our residential microgrid model features two overlapping networks: an electrical grid and an information network.

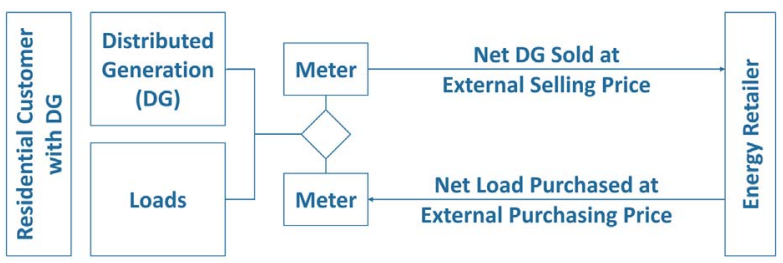

Fig. 2. Principal configuration of the net purchase and sale mechanism. The basic set-up features two different meters that independently track and bill net distributed generation and net load. 


\section{Electricity Rate Structure}

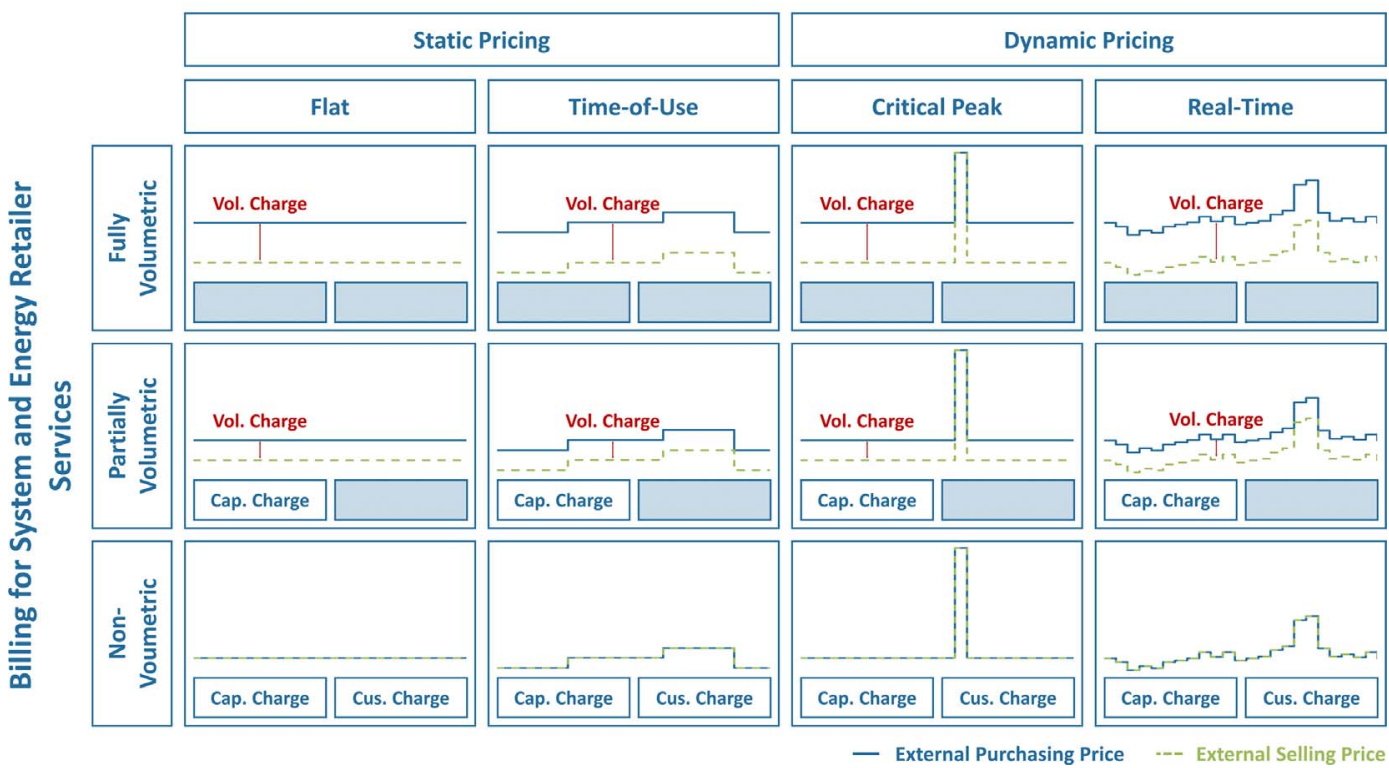

Fig. 3. Classification of the analyzed twelve net purchase and sale tariffs. Each tariff features a different combination of service charges and electricity rate structures.

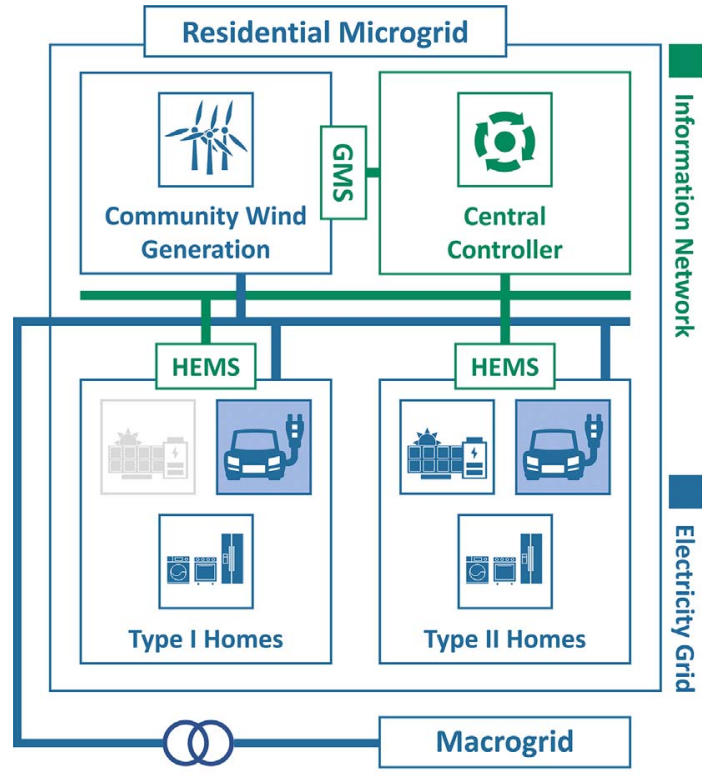

Point of Common Coupling

Fig. 4. High-level model of the simulated centrally controlled residential microgrids. The constituent homes and the community wind turbines are connected via a distributed electricity grid and an information network managed by the central controller. Both type I and type II homes can (optionally) feature an electric vehicle.

The microgrid's basic building blocks are two types of homes. Those belonging to type I represent customers with smart household devices but without microgeneration. Those belonging to type II, on the other hand, have solar panels. To leverage the full potential of residential solar [41] and to increase readiness for peak-based charges [23], all our model's type II homes also feature battery storage. Certain type I and type II households also own electric vehicles, ${ }^{2}$ and the microgrid additionally incorporates several small (communally owned) micro wind turbines. As a whole, the microgrid is connected to the macrogrid through a single point of common coupling.

\footnotetext{
${ }^{2}$ As detailed in Section 4, we modeled electric vehicles whenever we had EV charging data for the sampled Pecan Street home.
}

The information network interlinks all these energy sources and residential loads. Each homeowner has a home energy management system (HEMS) that tracks the home's basic electric parameters and sends this information to the central energy management system. This central controller subsequently combines this information with data on the storage and generation levels of the community installations, whereupon it curtails distributed generation, initiates battery (dis-) charging, and triggers load shifting. The resulting operational parameters are frequently sent back to the individual management systems to regulate power generation and consumption.

\subsection{Central control mechanism}

The central control mechanism optimizes the residential microgrid's electricity bill. While its details vary slightly with each tariff offered by the energy retailer, its key objective is to minimize costly energy purchases, maximize revenues from energy sales, and reduce costs from capacity charges. To this end, the mechanism considers distributed generation curtailment, schedules the microgrid's shiftable loads, and selects the battery-charging trajectory that best matches demand and the available distributed generation from wind and solar energy. We explain how we implemented these functions with a mixed integer linear program below.

\subsubsection{Battery storage modeling}

Eq. (1) guarantees that the mechanism correctly accounts for the initial state-of-charge of all battery units. Starting in the second optimization period, Eq. (2) maps the state-of-charge trajectory of all batteries over the simulation horizon. Constraint (3) imposes limits on the amount of energy the battery units can hold, reflecting the fact that batteries cannot charge beyond their physical capacity. It also limits the depth of discharge if a minimum state-of-charge is required to avoid early or otherwise undue degradation. Constraint (4) limits the charging and discharging rate to the parameters specified by the battery manufacturer. Constraints (5) and (6) ensure that batteries cannot charge and discharge at the same time and that charging cannot be modeled as negative discharging and vice versa.

$\operatorname{soc}_{t}=$ SoC $_{\text {init }}$ if $\mathrm{t}=1$

$\operatorname{soc}_{t}=\operatorname{soc}_{t-1}+$ RTE $\cdot c_{t}-d_{t} \quad \forall t: t>1$ 
$\operatorname{soc}_{\mathrm{t}} \geqslant \operatorname{SoC}_{\min }, \operatorname{soc}_{\mathrm{t}} \leqslant \mathrm{BC} \quad \forall \mathrm{t}$

$\mathrm{c}_{\mathrm{t}} \leqslant \mathrm{MCR}, \mathrm{d}_{\mathrm{t}} \leqslant \operatorname{MDR} \quad \forall \mathrm{t}$

$\mathrm{c}_{\mathrm{t}} \cdot \mathrm{d}_{\mathrm{t}}=0 \quad \forall \mathrm{t}$

$c_{t} \geqslant 0, d_{t} \geqslant 0 \quad \forall t$

\subsubsection{Smart household appliance and electric vehicle modeling}

Constraints (7)-(13) model the load-shifting process for smart household appliances and electric vehicles. Each of these smart loads is represented by a set of binary decision variables $x_{h, i, t}$ and $y_{h, i, t}$. The $x$ variables are one if smart load $i$ is scheduled in period $t$ and can be attributed to home $h$. The $y$ variables are one when the smart load has terminated, which prevents repeated scheduling. Constraint (7) matches the smart loads to the respective home they belong to. Constraints (8) and (9) ensure that the mechanism schedules each smart load and does not interrupt it. Constraint (10) limits the scheduling windows to the user-defined timeframes specified in the $U P_{i, t}$ parameters. Constraints (11) and (12) ensure that the mechanism does not reschedule a terminated load. Finally, constraint (13) defines the activation variables $x$ and $y$ as binary.

$\mathrm{x}_{\mathrm{h}, \mathrm{i}, \mathrm{t}} \leqslant \mathrm{AH}_{\mathrm{h}, \mathrm{i}} \quad \forall \mathrm{h}, \mathrm{i}, \mathrm{t}$

$\sum_{\mathrm{t}=1}^{\mathrm{T}} \mathrm{x}_{\mathrm{h}, \mathrm{i}, \mathrm{t}}=\mathrm{PT}_{\mathrm{i}} \quad \forall \mathrm{h}, \mathrm{i}$

$\left(\mathrm{x}_{\mathrm{h}, \mathrm{i}, \mathrm{t}-1}-\mathrm{x}_{\mathrm{h}, \mathrm{i}, \mathrm{t}}\right)-\mathrm{y}_{\mathrm{h}, \mathrm{i}, \mathrm{t}} \leqslant 0 \quad \forall \mathrm{h}, \mathrm{i}, \mathrm{t}: \mathrm{t}>1$

$\mathrm{x}_{\mathrm{h}, \mathrm{i}, \mathrm{t}} \leqslant \mathrm{UP}_{\mathrm{i}, \mathrm{t}} \quad \forall \mathrm{h}, \mathrm{i}, \mathrm{t}$

$\mathrm{x}_{\mathrm{h}, \mathrm{i}, \mathrm{t}}+\mathrm{y}_{\mathrm{h}, \mathrm{i}, \mathrm{t}} \leqslant 1 \quad \forall \mathrm{h}, \mathrm{i}, \mathrm{t}$

$\mathrm{y}_{\mathrm{h}, \mathrm{i}, \mathrm{t}-1}-\mathrm{y}_{\mathrm{h}, \mathrm{i}, \mathrm{t}} \leqslant 0 \quad \forall \mathrm{h}, \mathrm{i}, \mathrm{t}: \mathrm{t}>1$

$\mathrm{x}_{\mathrm{h}, \mathrm{i}, \mathrm{t}} \in\{0 ; 1\}, \mathrm{y}_{\mathrm{h}, \mathrm{i}, \mathrm{t}} \in\{0 ; 1\} \quad \forall \mathrm{h}, \mathrm{i}, \mathrm{t}$

\subsubsection{Distributed generation, power balance, and peak load modeling}

Constraints (14) and (15) safeguard that the demand-supply balance always holds. Additionally, they define $z_{d_{t}}$ as the microgrid's external net demand and $z_{s_{t}}$ as the amount of net supply in period t. Constraints (16) and (17) are introduced so that $p$ represents the highest absolute net imbalance (net load or generation peak). Constraint (18) defines $s g c_{t}$ and $w g c_{t}$ as distributed generation curtailment factors for solar and wind power respectively.

$\sum_{h, i} \mathrm{PC}_{\mathrm{i}} \cdot \mathrm{x}_{\mathrm{h}, \mathrm{i}, \mathrm{t}}-\mathrm{Z}_{\mathrm{d}_{\mathrm{t}}}+\mathrm{z}_{\mathrm{st}}-\mathrm{d}_{\mathrm{t}}+\mathrm{c}_{\mathrm{t}}-\mathrm{FL}_{\mathrm{t}}=\mathrm{sgc}_{\mathrm{t}} \cdot \mathrm{SGen}_{\mathrm{t}}+\mathrm{wgc}_{\mathrm{t}} \cdot \mathrm{WGen}_{\mathrm{t}} \quad \forall \mathrm{t}$

$\mathrm{z}_{\mathrm{dt}_{\mathrm{t}}} \cdot \mathrm{z}_{\mathrm{st}_{\mathrm{t}}}=0, \mathrm{z}_{\mathrm{dt}} \geqslant 0, \mathrm{z}_{\mathrm{st}} \geqslant 0 \quad \forall \mathrm{t}$
$\mathrm{z}_{\mathrm{d}_{\mathrm{t}}}-\mathrm{p} \leqslant 0 \quad \forall \mathrm{t}$
$\mathrm{z}_{\mathrm{s}_{\mathrm{t}}}-\mathrm{p} \leqslant 0 \quad \forall \mathrm{t}$
$0 \leqslant \operatorname{sgc}_{t} \leqslant 1,0 \leqslant w g c_{t} \leqslant 1 \quad \forall t$

\subsubsection{Objective functions for the 12 microgrid tariffs}

The central controller's basic objective is to minimize the microgrid's electricity costs. Eq. (19) highlights the general blueprint we used to specify this objective for all twelve tariffs. Each period's power imbalance is remunerated at the applicable selling price $\mathrm{SP}_{t}$, provided the microgrid is a net producer. Surplus demand, on the other hand, is billed at the respective purchasing price $\mathrm{PP}_{\mathrm{t}}$. The partially and nonvolumetric tariffs additionally incur a capacity charge (CapC) multiplied with the highest absolute net imbalance $p$ over the optimization horizon $T$. The non-volumetric objective functions also incorporate a fixed customer charge (CusC). Table 1 details the exact specifications for each tariff.

$\min \mathrm{tc}=\mathrm{PP}_{\mathrm{t}} \cdot \sum_{\mathrm{t}} \mathrm{z}_{\mathrm{d}_{\mathrm{t}}}-\mathrm{SP}_{\mathrm{t}} \cdot \sum_{\mathrm{t}} \mathrm{z}_{\mathrm{st}_{\mathrm{t}}}+$ CapC $\cdot \mathrm{p}+\mathrm{CusC}$

\section{Evaluation framework instantiation}

To provide statistically meaningful results, while limiting computational overhead, we built 100 microgrid simulations, each covering a new 10-home residential microgrid during a randomly selected week in 2015. Our stylized microgrids are based in Austin, Texas. For their parametrization, we drew on the Pecan Street Dataport [29] for hourly load data and PV micro-generation. Pecan Street Inc. is an Austin, Texas-based research and development organization focused on examining residential water and energy usage. Its core database tracks disaggregated (measured per-device) customer energy data from more than 1300 volunteer homes, located mainly in Austin but also in Colorado and California. However, to approximate local microgrids, we only focused on Austin and filtered out those 263 Austin homes that had complete hourly load data for 2015. When evaluating different microgrid sizes, we found that size-related benefits considerably abate when a residential microgrid comprises more than ten homes. To keep a check on computational complexity, we thus limited our microgrids to 10 randomly selected homes each.

Similarly, we used Pecan Street's hourly wind speed measurements to infer wind generation from nine Fortis Alizé type small wind turbines by Fortis Wind B.V. [30]. We selected this configuration because, on average, the combined output of the homes' solar panels and of nine of these turbines was equal to the energy needs of our microgrids. To incorporate battery storage, we equipped each PV system owner in our microgrids with a Powerwall 2 by Tesla, Inc. [31]. Furthermore, we used Austin-specific wholesale electricity prices from the Electric Reliability

Table 1

Instantiation of the objective function for the examined twelve tariffs.

\begin{tabular}{|c|c|c|c|c|}
\hline Tariff & $\mathrm{PP}_{\mathrm{t}}$ & $\mathrm{SP}_{\mathrm{t}}$ & CapC & CusC \\
\hline Fully volumetric - Flat pricing & $\mathrm{FPP}_{\mathrm{FP}, \mathrm{FV}}$ & FSP & - & - \\
\hline Partially volumetric - Flat pricing & $\mathrm{FPP}_{\mathrm{FP}, \mathrm{PV}}$ & FSP & CapC & - \\
\hline Non-volumetric - Flat pricing & $\mathrm{FPP}_{\mathrm{FP}, \mathrm{NV}}$ & FSP & CapC & CusC $_{\mathrm{FP}}$ \\
\hline Fully volumetric - Time-of-use pricing & ToUPP $_{\mathrm{t}, \mathrm{FV}}$ & ToUSP $_{t}$ & - & - \\
\hline Partially volumetric - Time-of-use pricing & ToUPP $_{\mathrm{t}, \mathrm{PV}}$ & ToUSP $_{t}$ & CapC & - \\
\hline Non-volumetric - Time-of-use pricing & ToUPP $_{t, N V}$ & ToUSP $_{t}$ & CapC & $\mathrm{CusC}_{\mathrm{ToUP}}$ \\
\hline Fully volumetric - Critical peak pricing & $\max \left(\mathrm{FPP}_{\mathrm{CPP}, \mathrm{FV}}, \mathrm{CPP}_{\mathrm{t}}\right)$ & $\max \left(\mathrm{FSP}, \mathrm{CPP}_{\mathrm{t}}\right)$ & - & - \\
\hline Partially volumetric - Critical peak pricing & $\max \left(\mathrm{FPP}_{\mathrm{CPP}, \mathrm{PV}}, \mathrm{CPP}_{\mathrm{t}}\right)$ & $\max \left(\mathrm{FSP}, \mathrm{CPP}_{\mathrm{t}}\right)$ & CapC & - \\
\hline Non-volumetric - Critical peak pricing & $\max \left(\mathrm{FPP}_{\mathrm{CPP}, \mathrm{NV}}, \mathrm{CPP}_{\mathrm{t}}\right)$ & $\max \left(\mathrm{FSP}, \mathrm{CPP}_{\mathrm{t}}\right)$ & CapC & CusC $_{\mathrm{CPP}}$ \\
\hline Fully volumetric - Real-time pricing & $\mathrm{RTPP}_{\mathrm{t}, \mathrm{FV}}$ & $\mathrm{RTSP}_{\mathrm{t}}$ & - & - \\
\hline Partially volumetric - Real-time pricing & $\mathrm{RTPP}_{\mathrm{t}, \mathrm{PV}}$ & $\mathrm{RTSP}_{\mathrm{t}}$ & CapC & - \\
\hline Non-volumetric - Real-time pricing & $\mathrm{RTPP}_{\mathrm{t}, \mathrm{NV}}$ & $\mathrm{RTSP}_{\mathrm{t}}$ & CapC & CusC $_{\text {RTP }}$ \\
\hline
\end{tabular}


Council of Texas (ERCOT) [42] and Austin Energy tariffs [43] to calibrate and instantiate the twelve evaluation tariffs. Below, we detail these data points and explain how we fit them into our empirical evaluation model.

\subsection{Load data}

To transform electricity consumption of the sample homes from Austin into smart loads, we leveraged a recently popularized appliance classification [44-46]. In doing so, we distinguished between three types of loads. One, devices like refrigerators that run constantly and do not depend on user interaction, which is to say they produce fully automatically controllable loads. Since these loads are attributable to specific devices, they are flexible and can be run preemptively or delayed without inconvenience to users. Two, dishwashers and comparable appliances that run independently yet require initial activation. Such devices produce semi-automatically controllable loads, which are similarly flexible and can be scheduled within user-specified bounds. Three, any device that constantly 'interacts' with the user, such as a TV set, produces unshiftable fixed loads.

In contrast to semi-automatically controllable loads, which are highly flexible, fully automatically controllable loads can, as a general rule, only be shifted within a timeframe of less than a single hour [47]. Because of computational complexity, we limited our evaluation to an hourly scale and therefore simplified this classification by treating both the fully automatically controllable and the fixed loads as unshiftable. Only for the semi-automatically controllable loads did we infer flexibility. While we believe that this simplified approach can provide a conservative estimate of the potential of shiftable loads, we expect the operational effects, especially of shifting air conditioning (AC), to be even higher. Table 2 summarizes our revised device classification.

As shiftable devices generally remain plugged in even when idle, they generate a non-shiftable base load. We approximated this base load for each device by averaging all loads that fell below its overall mean load. We then subtracted this base load from the device's load curve and treated it like a non-shiftable load. To simply load scheduling, we ultimately turned the remaining shiftable loads into shiftable blocks as exemplified for a random dishwasher in Fig. 5. Each shiftable block has the same start and end point as well as the same total energy need as the shiftable load it approximates.

Fig. 6 depicts the weekly load profile of a 10-home microgrid before and after we turned these smart loads into shiftable blocks. The 'blockification' causes minor smoothing; the overall load curves, however, remain almost identical and highly correlated at $99 \%$.

To infer flexibility, we stipulated that users would allow shifting windows of various lengths in which the shiftable blocks could be scheduled. We calculated these windows by multiplying the block's duration with a normally distributed random factor (shifting window $=\mathrm{N}\left(\mu, \sigma^{2}\right) \times$ duration). In a preliminary analysis, we found that scaling the variance had negligible effects. We thus kept it constant at a value of 1 and varied only the expected value from 0 to 5 as discussed in Section 5.2.

\subsection{Distributed generation data}

Aside from disaggregated load data, Pecan Street also tracks power output levels of residential PV systems. Of the examined Austin homes, $56 \%(\mathrm{~N}=148)$ had such a system. The top row in Fig. 7 shows that while the average output (bold red $^{3}$ line) was rather low at $0.5 \mathrm{~kW}$, it was noticeably higher during summer months and generally peaked in the early afternoon.

While Pecan Street homes do not own micro wind turbines, the dataport does track Austin wind speeds. We translated these wind speeds into power outputs of stylized micro turbines by using the power curve of a popular small wind turbine model. Specifically, we selected the Fortis Alizé [30] as its power output most closely matched the energy needs of our sample microgrids. When equipped with nine Fortis Alizé, our microgrids, on average, self-generated $100 \%$ of their overall power needs and only required a macrogrid connection to cover temporal imbalances. The bottom panel of Fig. 7 shows the resulting wind power output in 2015 . The average hourly output equaled $6.55 \mathrm{~kW}$, its highest levels occurring between the months of April and September. Winds increased especially during the day and peaked at approximately $6 \mathrm{pm}$. Although the daily output patterns look similar for solar and wind power, we only found a moderate correlation of $14 \%$ which rose to $22 \%$ between April and September.

\subsection{Battery storage parameters}

Selecting both the right energy storage technology and the right size generally requires a thorough analysis of several factors, such as economies of scale, local electricity prices and tariffs, subsidies, and the power generation profiles of coupled microgeneration units $[48,49]$. To manage the complexity of our evaluation study, we simplified these considerations and assumed that each of the modeled type II homes would own a single default energy storage unit. For this unit, we chose the Powerwall 2, Tesla, Inc.'s current home battery model [31] as recent studies indicate its growing profitability [50,51]. The Powerwall 2 is a lithium-ion battery with $13.5 \mathrm{kWh}$ of usable capacity and a power level of $5 \mathrm{~kW}$ that effectively represents the maximum charging and discharging rate. The Powerwall 2's depth of discharge equals $100 \%$ and its round-trip efficiency amounts to $90 \%$. To minimize potential biases, we assumed that each Powerwall 2 was empty at the beginning of the simulation timeframe.

\subsection{Tariff calibration}

While calibrating the twelve tariffs, we faced two challenges which energy retailers will also need to tackle in the future. First, they will not know beforehand how residential microgrids will respond to a new tariff. Second, they will need to rely on potentially erroneous predictions of demand and supply patterns. We approached this double challenge by using a representative calibration load profile which an energy retailer might use to set new tariffs. Specifically, we built an average 10-home microgrid from all eligible 263 Austin homes and equipped this calibration microgrid with 9 Fortis Alizé type wind turbines to simulate a residential microgrid which serves $100 \%$ of its energy needs with DG and only relies on the macrogrid for intertemporal balancing. For an overview of the parameters used, please refer to Table 3 .

To specify the twelve tariffs, we first calculated the annual electricity bill this calibration microgrid would have incurred in 2015. This bill then served as a cost reference for all twelve tariffs, i.e., we calibrated all tariffs to produce the same annual costs as the calibration bill. This benchmark bill had two components: number one, the electricity cost pursuant to Austin Energy's tiered volumetric retail tariff [43] and

Table 2

Classification of available Pecan Street devices.

\begin{tabular}{ll}
\hline Shiftable devices & Non-shiftable devices \\
\hline Washing machines & Lighting \\
Dishwashers & Kitchen appliances \\
Dryers & Generic smart plugs \\
Electric vehicles & Air conditioning \\
& Freezers \\
& Furnaces \\
& Refrigerators \\
\hline
\end{tabular}




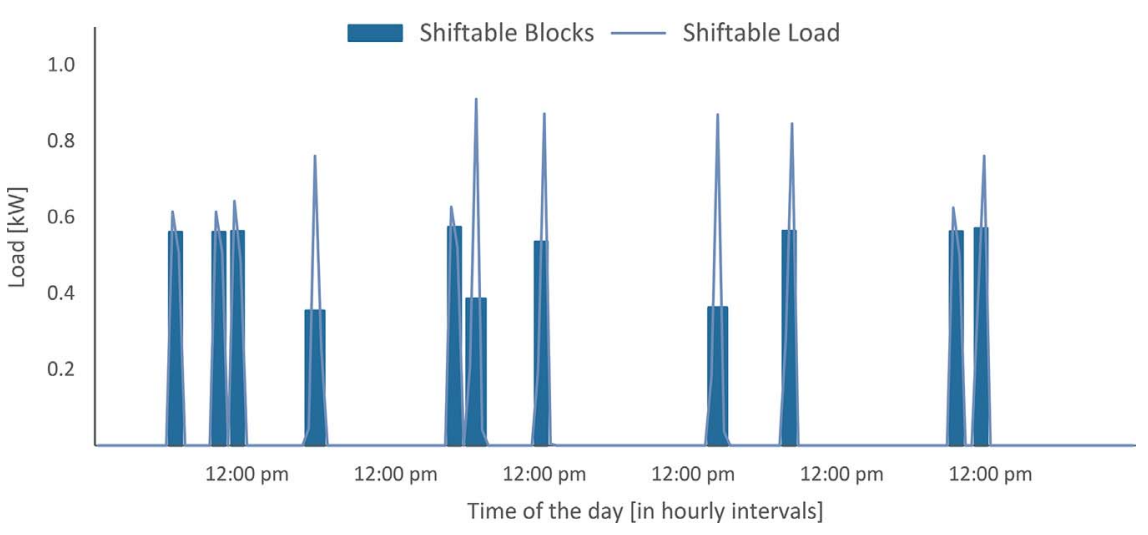

Fig. 5. Processed shiftable loads of a Pecan Street dishwasher. Each block approximates a shiftable load and has the same overall energy need as the original. number two, a generation credit (i.e., a feed-in tariff). As our residential microgrids do not qualify as small residential producers, we did not apply Austin's subsidized and elevated feed-in tariff, but instead remunerated distributed generation at the 2015 average wholesale market price.

For the fully volumetric flat tariff, we then proceeded as indicated in the first column of Table 4 . We began by calculating the total uncovered costs, i.e., the sum of the reference bill plus the costs and revenues of all net purchases and sales at the flat selling rate (set at the average wholesale market price). We subsequently derived the tariff's volumetric charge by dividing the uncovered costs by the amount of energy purchased from the energy retailer in 2015. The resulting flat purchasing price (including the volumetric charge) amounts to twice the current Austin Energy rate and exemplifies the "death spiral" of volumetric system service pricing [37]. As self-sufficient homes and microgrids draw ever less electricity from the grid, system operators will be tempted to considerably inflate peak-based charges to cover their macrogrid investments. This in turn raises the microgrid's incentives to reduce its electricity purchases, thus creating a "death spiral" of escalating prices and eroding revenues.

The calculation of the partially volumetric tariff mirrors the fully volumetric procedure. However, it also includes the impact of capacity charges on the calculation of the uncovered costs. We specified these capacity charges based on Austin Energy's applicable demand charges for commercial customers with a peak load greater or equal to $50 \mathrm{~kW}$ [43]. As shown in the second column of Table 4, costs from capacity charges contribute the largest part of the overall electricity bill, thus the resulting volumetric charge is only a third of its fully volumetric counterpart. The calculation of the non-volumetric alternative in the third column differs from the two volumetric approaches, as it does not break down the uncovered costs into a volumetric charge, instead billing them directly as a weekly customer charge. As in the partially volumetric scenario, the calculation starts with the reference bill and adjusts it for revenues from energy sales, costs of energy purchases, and costs related to the capacity charge. We spread these costs over all
52 weeks to arrive at a weekly customer charge of approximately 90 USD. Per home, this charge is three times higher than Austin Energy's current charge, which might elicit customer dissatisfaction if it is not properly related to the final electricity bill as indicated in Section 5 .

To calculate the respective charges for the time-of-use tariffs, we stipulated different rates for off-peak ( $12 \mathrm{am}-6 \mathrm{am} \& 10$ pm-12 am), mid-peak ( 6 am-2 pm \& 8 pm-10 pm) and peak ( 2 pm-8 pm) hours. This schedule mirrors Austin Energy's current ToU tariff for residential customers [43]. It also reflects typical ToU schedules [38]. Like the flat tariff rate, we defined these ToU selling rates as the average wholesale prices during each of the three periods. Based on these rates, we then calculated the uncovered costs and condensed them into a volumetric or customer charge respectively.

Similarly, the calibration of the critical peak tariffs mirrors the flat pricing procedure, yet it also includes a critical peak price for systemwide peak events. We based this price and the acceptable number of peak hours on a Pecan Street pilot in 2013/14 which evaluated critical peak pricing for single homes [52]. Specifically, we set a critical peak price of $0.64 \mathrm{USD} / \mathrm{kWh}$ (identical for electricity purchases and sales) for the 45 hours in 2015 with the highest wholesale market prices. These critical peak hours resulted either in additional costs, if the calibration microgrid had to buy electricity, or in further revenues, if it was supplying to the energy retailer at these hours. We subsequently reduced the uncovered costs by the resulting net critical peak costs, then followed the rest of the flat pricing routine.

As for the real-time tariff calibration, this adhered to the ToU procedure, but substituted wholesale market prices for the ToU rates. Please refer to the Appendix A for a more detailed step-by-step calibration of the time-of-use, critical-peak, and real-time tariffs.

\section{Evaluation results and tariff design implications}

In the following, we discuss the results of our 100 microgrid simulations. We also present a set of sensitivity analyses to illustrate the effects of varying levels of solar generation, wind generation, battery

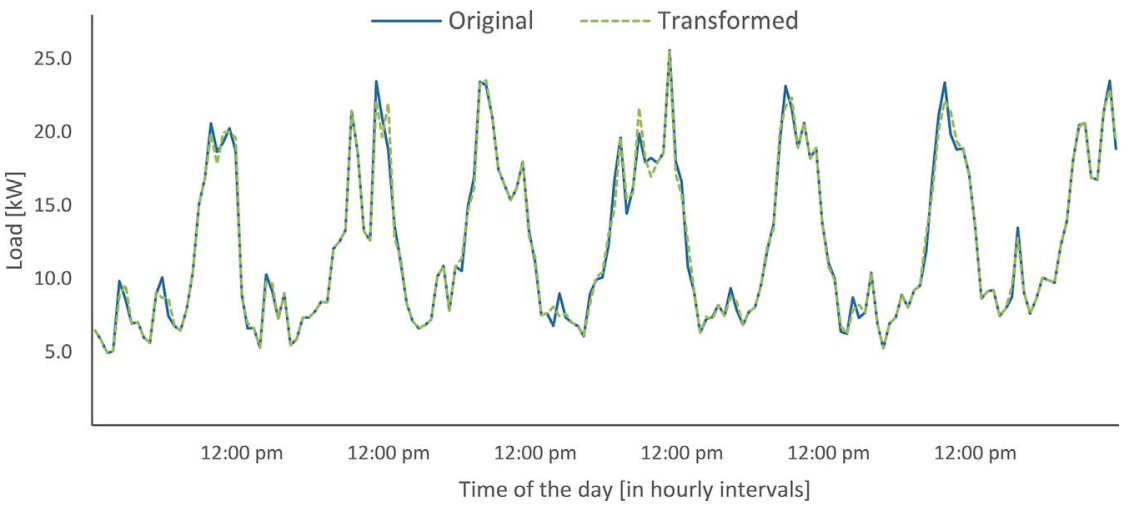

Fig. 6. Effects of transforming flexible loads into shiftable blocks. The figure shows the weekly load curve of a sample residential microgrid before and after 'blockification' of shiftable loads. 

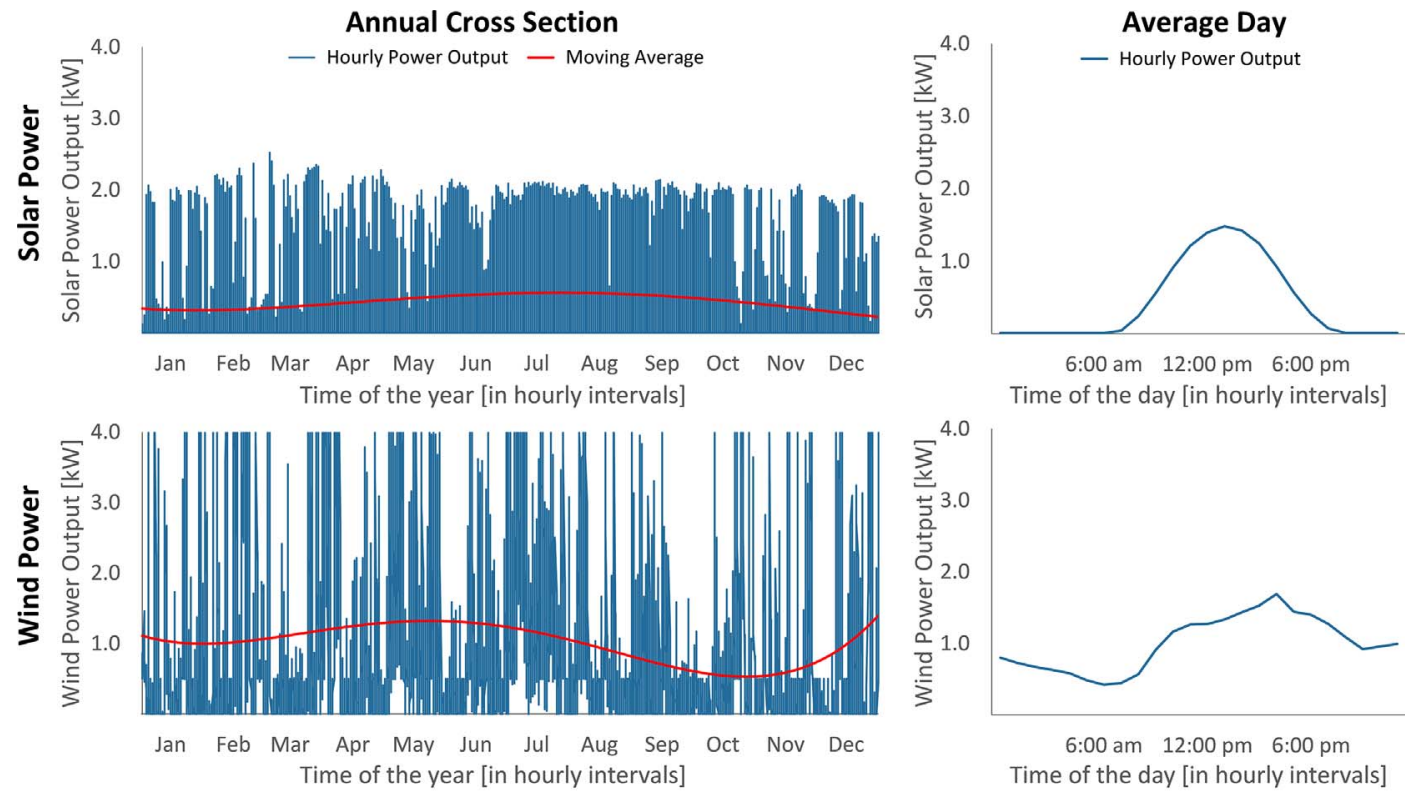

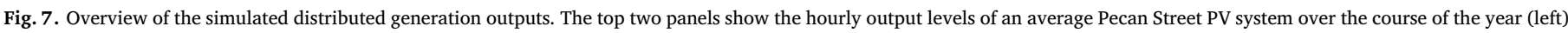

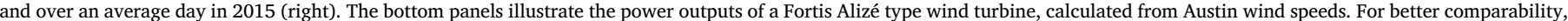
the bottom left panel does not depict power output levels beyond $4 \mathrm{~kW}$.

Table 3

Tariff calibration parameters.

\begin{tabular}{|c|c|c|}
\hline Calibration parameters & Instantiation & Source \\
\hline Predictive load profile & Load profile of an average 10-home residential microgrid equipped with nine Fortis Alizé type wind turbines & Pecan Street [29] \\
\hline Benchmark electricity tariff & Tiered Austin Energy volumetric tariff for residential customers & Austin Energy [43] \\
\hline Wholesale market prices & ERCOT Real-Time Settlement Point Prices (RTSPPs) calculated for the Austin Load Zone & ERCOT [42] \\
\hline Capacity charge & $\begin{array}{l}\text { Condensed Austin Energy demand charges as applicable to commercial customers with a peak load greater or equal to } \\
50 \mathrm{~kW}\end{array}$ & Austin Energy [43] \\
\hline Critical peak pricing parameters & Parameters from a critical peak pricing pilot by Pecan Street in 2013 and 2014 & Pecan Street [52] \\
\hline ToU schedule & Simplified version of Austin Energy's residential ToU schedule & Austin Energy [43] \\
\hline
\end{tabular}

Table 4

Calibration of the three flat tariffs.

\begin{tabular}{|c|c|c|c|}
\hline & Fully volumetric & Partially volumetric & Non-volumetric \\
\hline \multicolumn{4}{|l|}{ Definition of the flat selling price } \\
\hline $\mathrm{FSP}[\mathrm{USD} / \mathrm{kWh}]=\frac{1}{\mathrm{~T}} \cdot \sum_{\mathrm{t}=1}^{\mathrm{T}} \mathrm{RTSPP}_{\mathrm{t}}$ & 0.0247 & 0.0247 & 0.0247 \\
\hline \multicolumn{4}{|l|}{ Definition of the weekly capacity charge } \\
\hline CapC [USD/kW] & - & 3.7598 & 3.7598 \\
\hline \multicolumn{4}{|l|}{ Calculation of the total uncovered costs } \\
\hline Total 2015 electricity costs to be allocated [USD] & $13,953.1965$ & $13,953.1965$ & $13,953.1965$ \\
\hline+2015 revenues from net DG sales at FSP [USD] & 1227.3886 & 1227.3886 & 1227.3886 \\
\hline-2015 costs from net demand purch. at FPP $=$ FSP [USD] & 1205.2956 & 1205.2956 & 1205.2956 \\
\hline - 2015 costs from 52 weekly CapCs [USD] & - & 9325.9412 & 9325.9412 \\
\hline$=$ Total uncovered costs $[\mathrm{USD}]$ & $13,975.2895$ & 4649.3483 & 4649.3483 \\
\hline \multicolumn{4}{|l|}{ Calculation of the flat purchasing price } \\
\hline Total uncovered costs [USD] & $13,975.2895$ & 4649.3483 & - \\
\hline / Total amount of energy purchased in 2015 [kWh] & $48,840.6188$ & $48,840.6188$ & - \\
\hline$=\mathrm{VolC}_{\mathrm{FP}, \mathrm{x}}[\mathrm{USD} / \mathrm{kWh}]$ & 0.2861 & 0.0952 & - \\
\hline + FSP [USD/kWh] & 0.0247 & 0.0247 & 0.0247 \\
\hline$=\mathrm{FPP}_{\mathrm{FP}, \mathrm{x}}[\mathrm{USD} / \mathrm{kWh}]$ & 0.3108 & 0.1199 & 0.0247 \\
\hline \multicolumn{4}{|l|}{ Calculation of the weekly customer charge } \\
\hline Total uncovered costs [USD] & - & - & 4649.3483 \\
\hline / 52 weeks & - & - & 52.0000 \\
\hline$=$ Weekly CusC $C_{F P}[\mathrm{USD}]$ & - & - & 89.4105 \\
\hline
\end{tabular}


size, and consumer flexibility. Specifically, we scaled all these components from $0 \%$ to $200 \%$, re-simulating all 100 microgrid simulations for each new scenario. In total, we performed 61,200 simulation runs (12 tariffs $\times 51$ parameter combinations $\times 100$ residential microgrid instances). Each of these runs took approximately $3 \mathrm{~s}$ to solve on an 8 GB RAM computer with an Intel ${ }^{\circledR}$ Core $^{\mathrm{TM}}$ i5-4200U CPU with two cores @ $1.60 \mathrm{GHz}$, running Gurobi ${ }^{\circledR} 7.0 .0$.

\subsection{Baseline analysis}

To compare the twelve tariffs, we stipulated that an ideal tariff would have to reconcile the interests of energy retailers, residential microgrid operators, and system operators. First, we looked at the resulting electricity costs (key financial determinant for microgrid operators) and the degree to which the tariffs facilitated cost-effective pricing (important to energy retailers). We then analyzed the absolute peak load and the crest factor, i.e., the quotient of the absolute peak load and the root mean square of all loads. With these two measures, system operators can gauge capacity requirements for the point of common coupling (absolute peak loads) and the average degree of grid utilization (crest factors). Even though these measures are primarily relevant to system operators, it is essential that energy retailers and microgrid operators also take these two measures into account, since system operators will charge them for their contribution to system costs. We have summarized the results as averaged over the initial 100 simulation runs in Table 5 .

These figures suggest that fully volumetric tariffs are the least attractive alternative, as they fall short on all counts: in terms of energy bill savings, cost-effectiveness, and grid stabilization. Most microgrid operators would prefer partially volumetric tariffs. These tariffs offer the largest incentive for smart load management and promise two options for energy bill savings. Option one, reduce absolute peak loads. Option two, limit externally purchased energy. Energy retailers and system operators, on the other hand, would favor the more expensive non-volumetric alternatives as they (a) ensure that microgrid operators pay for system services as soon as they rely on the macrogrid, (b) warrant stable customer charge revenues, and (c) effectively reduce absolute peak loads and crest factors.

Meanwhile, the electricity rate structure has mere secondary effects. Certainly, critical peak pricing seems to promise the highest cost savings potential, followed by real-time, ToU, and finally flat pricing, but these minor cost benefits are essentially acquired at the cost of higher absolute peak loads and crest factors.

\subsection{Sensitivity analyses}

To test these findings for different microgrid configurations, we systematically varied the level of solar generation, wind generation, battery size, and consumer flexibility as indicated in Fig. 8.

\subsubsection{Electricity costs}

Panels ' $1 \mathrm{a}$ ' and '2a' of Fig. 8 indicate that the overall electricity costs are lower for microgrids with higher solar and wind generation capacity. However, each additional unit offers comparatively fewer energy bill reductions (i.e., decreasing marginal savings). This deceleration has various causes, depending on the employed charges. With volumetric billing, each kWh of distributed generation that supersedes power imports saves volumetric charges. Yet with higher levels of DG, there are fewer imports to supersede, so marginal volumetric charge savings decrease. Similarly, capacity charges lead to decreasing marginal cost savings. They encourage generation curtailment whenever generation levels rise considerably beyond the overall average. The microgrid operator thus chooses to waste peak generation to save on capacity costs. While the microgrid operator cannot eliminate these costs without disconnecting from the macrogrid, panel '3a' nevertheless indicates that they can be lowered by leveraging battery storage. This effect, however, is counteracted by the fact that battery storage has a decreasing marginal impact on electricity costs, i.e., each further addition of battery capacity reduces electricity bills by a smaller margin.

Panel ' $5 \mathrm{a}$ ' conjoins the individual analyses by simultaneously scaling all four components to pinpoint the effects of different levels of collective "capacity investment" by the microgrid's participants. As shown, non-volumetric tariffs incur a sizeable customer charge, yet they are the most economical option up to $80 \%$ of capacity investment. In this interval, the benefits of cheaper purchasing rates seem to outweigh the volumetric charge savings that the microgrid can obtain by minimizing energy purchases. In the $80 \%$ to $160 \%$ interval, the volumetric charge elimination strategy pays off and partially volumetric tariffs are cheaper than their non-volumetric counterparts. For capacity investment beyond $160 \%$, residual power imports are so low that flat tariffs (without capacity charges for generation peaks) are the cheapest option.

\subsubsection{Absolute peak loads}

As indicated in panels ' $1 b$ ' to ' $5 b$ ', absolute peak loads coincide almost perfectly for all tariffs with capacity charges. With increasing levels of capacity investments, absolute peak loads rapidly drop and remain at a stable, low level. In contrast, the fully volumetric tariffs feature a markedly different pattern and absolute peak loads escalate

Table 5

Baseline simulation results.

\begin{tabular}{|c|c|c|c|}
\hline Pricing scheme & Electricity costs [in USD] (and in \% of the reference bill) & Absolute peak load [in kW] & Crest factor \\
\hline Fully Volumetric - Flat & $189.29(75 \%)$ & 50.19 & 3.78 \\
\hline Fully Volumetric - ToU & 186.83 & 57.99 & 4.14 \\
\hline Fully Volumetric - RT & 181.83 & 64.05 & 4.37 \\
\hline Fully Volumetric - CP & 179.84 & 51.26 & 3.80 \\
\hline Non-Volumetric - Flat & 133.82 & 9.67 & 1.20 \\
\hline Non-Volumetric - ToU & 132.65 & 9.67 & 1.09 \\
\hline Non-Volumetric - RT & 128.35 & 10.56 & 1.08 \\
\hline Non-Volumetric - CP & 127.26 & 10.73 & 1.23 \\
\hline Partially Volumetric - Flat & 109.79 & 9.67 & 1.35 \\
\hline Partially Volumetric - ToU & 109.54 & 9.67 & 1.33 \\
\hline Partially Volumetric - RT & 107.75 & 10.12 & 1.34 \\
\hline Partially Volumetric - CP & $104.86(43 \%)$ & 10.63 & 1.39 \\
\hline Especially relevant to & Microgrid operators & System operators & \\
\hline
\end{tabular}


Electricity Costs
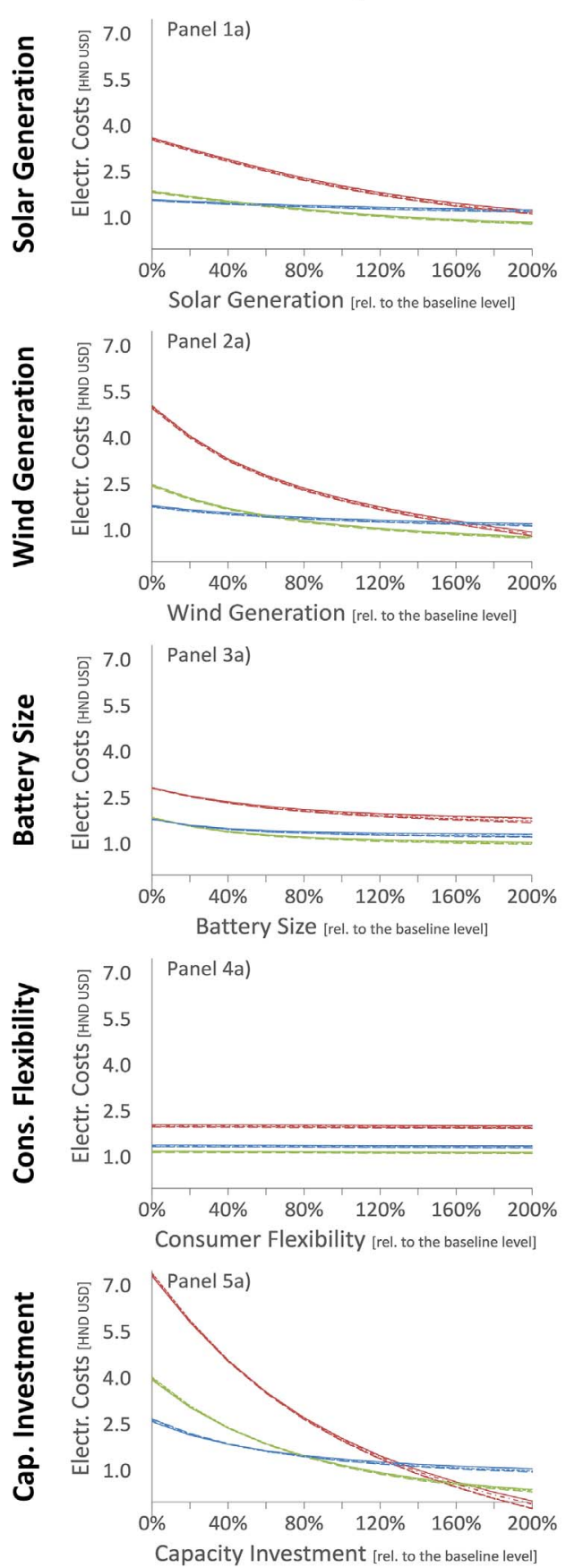

— Fully Volum. - Flat _ _ Fully Volum - ToU

- - Fully Volum. - CP --. Fully Volum. - RT
Absolute Peak Load
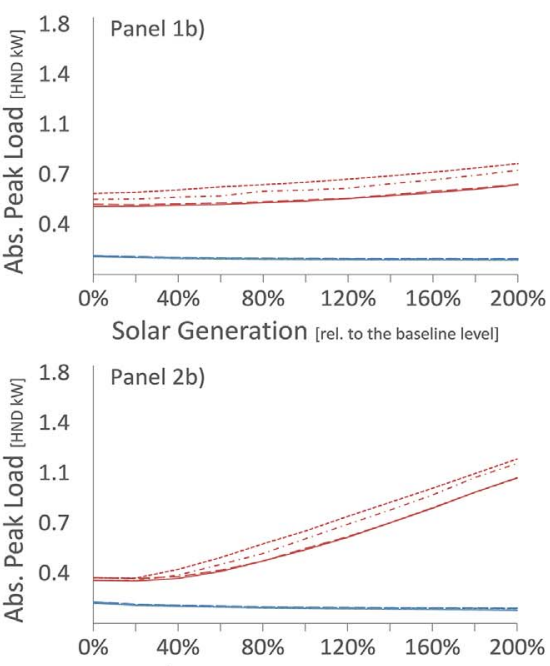

Wind Generation [rel. to the baseline level]
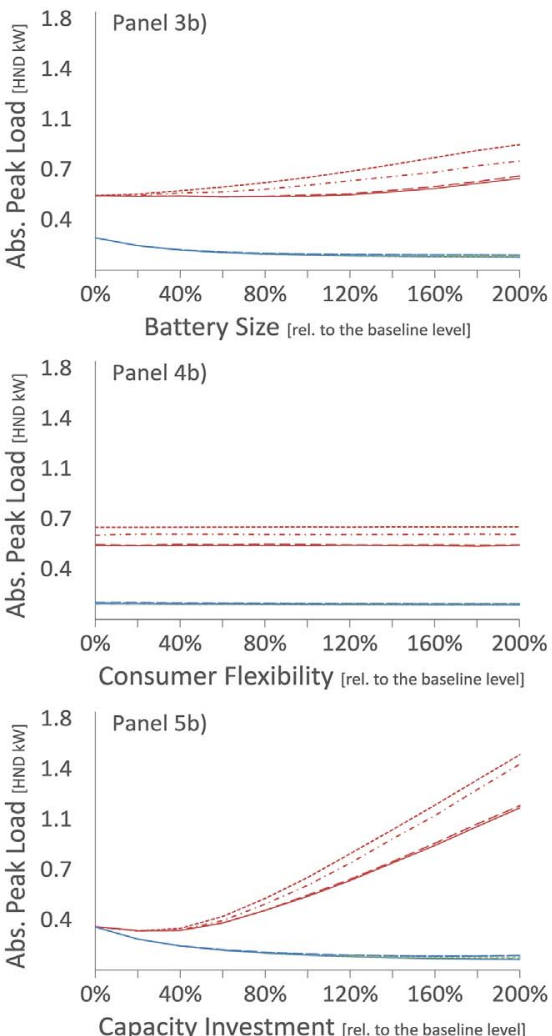

_ Part. Volum. - Flat _. Part. Volum. - ToU

- - Part. Volum. - CP -.. Part. Volum. - RT
Crest Factor
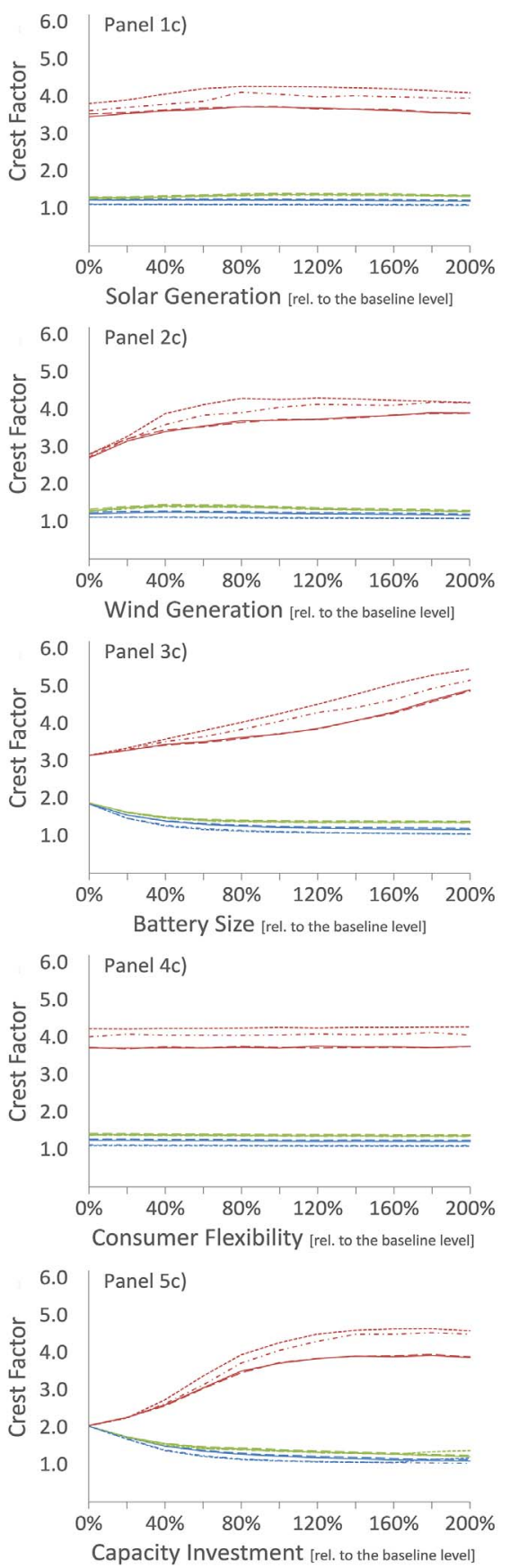

- Non-Volum. - Flat _ - Non-Volum. - ToU

- - Non-Volum. - CP -.. Non-Volum. - RT

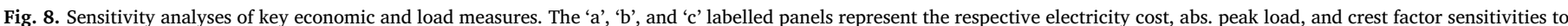

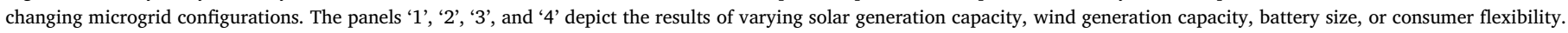
Panels marked ' 5 ' simultaneously scale all four parameters.

perceptibly. This steep rise is most apparent in the case of real-time pricing, which systematically encourages microgrid operators to exploit temporal price differences with little regard for their load and generation profile. Higher levels of distributed generation and battery storage reinforce these peak effects (panels ' $1 \mathrm{~b}$ ' to ' $3 \mathrm{~b}$ '), whereas consumer flexibility tends to have negligible effects (panel '4b').

\subsubsection{Crest factors}

While the partially volumetric and non-volumetric tariffs hardly differ in their effect on peak loads, they do vary, if only slightly, in their impact on crest factors (panels ' $1 c$ ' to ' $5 c$ '). As the non-volumetric tariffs offer the same purchasing and selling prices, they effectively encourage more energy trading, thus inflating crest factors. 
Unlike peak loads, the crest factors of the fully volumetric tariffs do not escalate indefinitely. Instead, they reach a plateau where the microgrid turns into a relatively stable net producer. Even though this renders the microgrid's load profile more balanced, it does little to reduce its drastic generation peaks.

\subsection{Tariff design implications}

Based on these findings, we argue that any future residential microgrid tariff should avoid volumetric billing in favor of capacity and customer charges.

Capacity charges in particular will incentivize microgrid operators to balance their load and generation profiles. They should therefore apply to any microgrid that connects to the macrogrid, whether it acts as an independent power producer (IPP) or a large consumer. Effective distribution grid management might furthermore require variable capacity charges. These charges could, e.g., increase linearly with absolute peak loads and/or include jumps for breaking personalized peak barriers [28]. Such variations, however, should fairly account for the benefits of reduced peaking infrastructure and allocate network costs equitably $[27,28,35,53]$.

Furthermore, customer charges would allow energy retailers to lock in stable cash-flows. In competitive retail markets, however, energy retailers will need to adapt these charges to their service levels. Customer charges could thus be higher for microgrids which request flat rates (i.e., wholesale price risk intermediation) and significant electricity deliveries. This customer segment could, for instance, include many urban apartment buildings with too little roof area to install large arrays of solar panels or a micro wind turbine. Meanwhile, the customer charge should be lower for self-sufficient microgrids that require little or no macrogrid support and price intermediation. Microgrid operators with significant distributed generation which only rely on their energy retailer for wholesale market brokerage might ultimately demand an even lower charge.

As for tariffs with capacity and customer charges, these would also enable energy retailers and microgrid operators to freely negotiate rate structures without negatively affecting local macrogrid stability or threatening the energy retailer's revenue base. Ultimately, however, we expect that critical peak pricing will play a prominent role, as it poses very moderate price risks to microgrid operators and yet encourages demand reductions during the few extreme peaks which determine most macrogrid costs [35]. We also caution against touting real-time pricing as an economic panacea for residential tariff design [19,54], as many microgrid operators might be reluctant to assume the implicit price risk. Energy retailers, on the other hand, can easily manage this risk by creating sufficiently large customer portfolios and trading in the wholesale market [55]. Nevertheless, real-time wholesale pricing might become the preferred option for microgrids that mainly act as IPPs. In this case, energy retailers would act as aggregators and permit wholesale market integration, even if the individual power outputs would not meet minimum size requirements for wholesale market participation.

\section{Conclusion}

Residential microgrids could resolve many technical challenges inherent to distributed residential power generation [3]. Energy retailers, however, still lack effective tariffs for these prospective customers. Our study attempts to fill this gap and empirically reviews twelve net purchase and sale tariffs with a residential microgrid simulation framework.

Based on these simulations, we made a series of discoveries. Number one, fully volumetric billing would encourage shortsighted load management at the expense of drastic absolute peak loads and macrogrid instability. Ultimately, it might also threaten the energy retailer's revenue base, as microgrid operators can easily circumvent volumetric charges by reducing macrogrid imports. Number two, our study indicates that time-varying rates (ToU, critical peak, and real-time) may offer certain financial benefits for microgrid operators, yet can also result in more extreme load profiles. However, if residential microgrid tariffs were to bill system costs via capacity charges, time-varying rates would have little impact on energy bills, energy loads, and generation profiles. Number three, our analyses indicate that a combination of capacity and customer charges would ensure that microgrid operators present stable load and generation profiles, while also guaranteeing that they pay their share of overall system costs. This share would fairly reflect the microgrid's actual dependence on the macrogrid and the energy retailer's services. Energy retailers might therefore want to offer residential microgrid tariffs with capacity and customer charges as well as negotiable rate structures. Such tariffs could lower the microgrid operator's electricity bill and foster peak shaving, while also facilitating stable allocation of energy retailer and system costs (distribution and transmission).

These results are robust in our evaluation setting. We are aware, however, that they are based on an evaluation study that naturally simplifies certain aspects which would require complex modeling in real-world settings [56]. It is important to note that our evaluation explicitly stipulates a net purchase and sale policy rather than one of the more common feed-in tariff or net-metering mechanisms. By the same token, energy retailers in net metering jurisdictions could easily mirror the suggested non-volumetric tariffs. These tariffs feature the same (dynamic) purchasing and selling rates and would thus also qualify for net metering. However, our tariffs are not directly transferable to jurisdictions with feed-in policies, as these directly price distributed generation rather than net generation. Additionally, we did not reflect the flexibility of residential loads that are shiftable for less than an hour. Hence we did not account for shiftable thermal loads such as refrigerators, furnaces, and air conditioning, though the latter contribute significantly to summer peak loads $[37,57,58]$. Prior research, on the other hand, indicates that AC units would respond quite similarly to different rate structures [59]. We also believe that dropping our assumption of perfect information would moderate the identified tariff effects and paint a more ambiguous picture. Without perfect foresight, electricity bill savings would probably be less pronounced, load peaks and crest factors would be higher, and optimization against timevarying rates would be more difficult. Nevertheless, we believe that our key results would remain unchanged if we were to include "real-word" uncertainty. Volumetric billing would still cause unstable load profiles, capacity charges would still moderate the effects of time-varying rates, and non-volumetric billing would still warrant stable cost-allocation and encourage microgrid operators to cap load and generation peaks.

To put it in a nutshell, we are thus confident that, with the indicated caveats, our study can serve as a practical and broad reference point for future residential microgrid tariff design.

\section{Appendix A. Tariff calibration for the ToU, critical peak, and real-time pricing tariffs}

See Tables 6-8. 
Table 6

Calibration of the three time-of-use tariffs.

\begin{tabular}{|c|c|c|c|}
\hline & Fully volumetric & Partially volumetric & Non-volumetric \\
\hline \multicolumn{4}{|l|}{ Definition of the ToU selling prices } \\
\hline ToUS $\mathrm{P}_{1}[\mathrm{USD} / \mathrm{kWh}]=$ Average RTSPP - off-peak & 0.0179 & 0.0179 & 0.0179 \\
\hline ToUS $\mathrm{P}_{2}[\mathrm{USD} / \mathrm{kWh}]=$ Average RTSPP - mid-peak & 0.0256 & 0.0256 & 0.0256 \\
\hline ToUS $\mathrm{P}_{3}[\mathrm{USD} / \mathrm{kWh}]=$ Average RTSPP - peak & 0.0320 & 0.0320 & 0.0320 \\
\hline \multicolumn{4}{|l|}{ Definition of the weekly capacity charge } \\
\hline CapC $[\mathrm{USD} / \mathrm{kW}]$ & - & 3.7598 & 3.7598 \\
\hline \multicolumn{4}{|l|}{ Calculation of the total uncovered costs } \\
\hline Total 2015 electricity costs to be allocated [USD] & $13,953.1965$ & $13,953.1965$ & $13,953.1965$ \\
\hline+2015 revenues from net DG sales at ToUSP $\mathrm{t}_{t}$ [USD] & 1317.0199 & 1317.0199 & 1317.0199 \\
\hline-2015 costs from net dem. purch. at ToUPP $P_{t}=$ ToUSP $_{t}[U S D]$ & 1203.1101 & 1203.1101 & 1203.1101 \\
\hline - 2015 costs from 52 weekly CapCs [USD] & - & 9325.9412 & 9325.9412 \\
\hline$=$ Total uncovered costs $[\mathrm{USD}]$ & $14,067.1062$ & 4741.1651 & 4741.1651 \\
\hline \multicolumn{4}{|l|}{ Calculation of the ToU purchasing prices } \\
\hline Total uncovered costs [USD] & $14,067.1062$ & 4741.1651 & - \\
\hline / Total amount of energy purchased in 2015 [kWh] & $48,840.6188$ & $48,840.6188$ & - \\
\hline$=\mathrm{VolC}_{\mathrm{ToUP}, \mathrm{x}}[\mathrm{USD} / \mathrm{kWh}]$ & 0.2880 & 0.0971 & - \\
\hline ToUP $\mathrm{P}_{1}[\mathrm{USD} / \mathrm{kWh}]=$ ToUS $\mathrm{P}_{1}+\mathrm{VolC}_{\mathrm{ToUP}, \mathrm{x}}$ & 0.3060 & 0.1150 & 0.0179 \\
\hline ToUP $\mathrm{P}_{2}[\mathrm{USD} / \mathrm{kWh}]=$ ToUS $\mathrm{P}_{2}+\mathrm{VolC}_{\mathrm{ToUP}, \mathrm{x}}$ & 0.3137 & 0.1227 & 0.0256 \\
\hline ToUP $\mathrm{P}_{3}[\mathrm{USD} / \mathrm{kWh}]=$ ToUS $\mathrm{P}_{3}+\mathrm{VolC}_{\mathrm{ToUP}, \mathrm{x}}$ & 0.3201 & 0.1291 & 0.0320 \\
\hline \multicolumn{4}{|l|}{ Calculation of the weekly customer charge } \\
\hline Total uncovered costs [USD] & - & - & 4741.1651 \\
\hline / 52 weeks & - & - & 52.0000 \\
\hline$=$ Weekly CusC $\mathrm{ToUP}_{\text {[USD] }}$ & - & - & 91.1763 \\
\hline
\end{tabular}

Table 7

Calibration of the three critical peak tariffs.

\begin{tabular}{|c|c|c|c|}
\hline & Fully volumetric & Partially volumetric & Non-volumetric \\
\hline \multicolumn{4}{|l|}{ Definition of the flat selling price } \\
\hline FSP $[\mathrm{USD} / \mathrm{kWh}]=\frac{1}{\mathrm{~T}} \cdot \sum_{\mathrm{t}=1}^{\mathrm{T}} \mathrm{RTSPP}_{\mathrm{t}}$ & 0.0247 & 0.0247 & 0.0247 \\
\hline \multicolumn{4}{|l|}{ Definition of the critical peak price } \\
\hline $\mathrm{CPP}$ [USD/kWh] & 0.6400 & 0.6400 & 0.6400 \\
\hline \multicolumn{4}{|l|}{ Definition of the weekly capacity charge } \\
\hline CapC [USD/kW] & - & 3.7598 & 3.7598 \\
\hline \multicolumn{4}{|l|}{ Calculation of the total uncovered costs } \\
\hline Total 2015 electricity costs to be allocated [USD] & $13,953.1965$ & $13,953.1965$ & $13,953.1965$ \\
\hline+2015 revenues from net DG sales at FSP [USD] & 1227.3886 & 1227.3886 & 1227.3886 \\
\hline-2015 costs from net dem. purch. at FPP = FSP [USD] & 1205.2956 & 1205.2956 & 1205.2956 \\
\hline+2015 revenues from CPP events [USD] & 61.8788 & 61.8788 & 61.8788 \\
\hline - 2015 costs from CPP events [USD] & 173.1284 & 173.1284 & 173.1284 \\
\hline - 2015 costs from 52 weekly CapCs [USD] & - & 9325.9412 & 9325.9412 \\
\hline$=$ Total uncovered costs $[\mathrm{USD}]$ & $13,864.0399$ & 4538.0987 & 4538.0987 \\
\hline \multicolumn{4}{|l|}{ Calculation of the flat purchasing price } \\
\hline Total uncovered costs [USD] & $13,864.0399$ & 4538.0987 & - \\
\hline / Total amount of energy purchased in 2015 [kWh] & $48,840.6188$ & $48,840.6188$ & - \\
\hline$=\mathrm{VolC}_{\mathrm{CPP}, \mathrm{x}}[\mathrm{USD} / \mathrm{kWh}]$ & 0.2839 & 0.0929 & - \\
\hline + FSP [USD/kWh] & 0.0247 & 0.0247 & 0.0247 \\
\hline$=\mathrm{FPP}_{\mathrm{CPP}, \mathrm{x}}[\mathrm{USD} / \mathrm{kWh}]$ & 0.3085 & 0.1176 & 0.0247 \\
\hline \multicolumn{4}{|l|}{ Calculation of the weekly customer charge } \\
\hline Total uncovered costs [USD] & - & - & 4538.0987 \\
\hline / 52 weeks & - & - & 52.0000 \\
\hline$=$ Weekly CusC $\mathrm{CPP}_{\mathrm{CPSD}}$ [U & - & - & 87.2711 \\
\hline
\end{tabular}


Table 8

Calibration of the three real-time tariffs.

\begin{tabular}{|c|c|c|c|}
\hline & Fully volumetric & Partially volumetric & Non-volumetric \\
\hline \multicolumn{4}{|l|}{ Definition of the real-time selling prices } \\
\hline $\mathrm{RTSP}_{\mathrm{t}}[\mathrm{USD} / \mathrm{kWh}]=\mathrm{RTSPP}_{\mathrm{t}}$ & $\mathrm{RTSPP}_{\mathrm{t}}$ & $\operatorname{RTSPP}_{\mathrm{t}}$ & $\operatorname{RTSPP}_{\mathrm{t}}$ \\
\hline \multicolumn{4}{|l|}{ Definition of the weekly capacity charge } \\
\hline CapC $[U S D / k W]$ & - & 3.7598 & 3.7598 \\
\hline \multicolumn{4}{|l|}{ Calculation of the total uncovered costs } \\
\hline Total 2015 electricity costs to be allocated [USD] & $13,953.1965$ & $13,953.1965$ & $13,953.1965$ \\
\hline+2015 revenues from net DG sales at $\mathrm{RTSP}_{t}$ [USD] & 1264.0604 & 1264.0604 & 1264.0604 \\
\hline-2015 costs from net dem. purch. at $\mathrm{RTPP}_{\mathrm{t}}=\mathrm{RTSP}_{\mathrm{t}}[\mathrm{USD}]$ & 1217.1487 & 1217.1487 & 1217.1487 \\
\hline - 2015 costs from 52 weekly CapCs [USD] & - & 9325.9412 & 9325.9412 \\
\hline$=$ Total uncovered costs $[\mathrm{USD}]$ & $14,000.1082$ & 4674.1670 & 4674.1670 \\
\hline \multicolumn{4}{|l|}{ Calculation of the real-time purchasing prices } \\
\hline Total uncovered costs [USD] & $14,000.1082$ & 4674.1670 & - \\
\hline / Total amount of energy purchased in 2015 [kWh] & $48,840.6188$ & $48,840.6188$ & - \\
\hline$=\operatorname{VolC}_{\mathrm{RTP}, \mathrm{x}}[\mathrm{USD} / \mathrm{kWh}]$ & 0.2866 & 0.0957 & - \\
\hline$+\mathrm{RTSP}_{\mathrm{t}}[\mathrm{USD} / \mathrm{kWh}]$ & $\mathrm{RTSPP}_{\mathrm{t}}$ & $\mathrm{RTSPP}_{\mathrm{t}}$ & $\mathrm{RTSPP}_{\mathrm{t}}$ \\
\hline$=\mathrm{RTPP}_{\mathrm{t}}[\mathrm{USD} / \mathrm{kWh}]$ & $\mathrm{RTSPP}_{\mathrm{t}}+0.2866$ & $\mathrm{RTSPP}_{\mathrm{t}}+0.0957$ & $\mathrm{RTSPP}_{\mathrm{t}}$ \\
\hline \multicolumn{4}{|l|}{ Calculation of the weekly customer charge } \\
\hline Total uncovered costs [USD] & - & - & 4674.1670 \\
\hline / 52 weeks & - & - & 52.0000 \\
\hline$=$ Weekly CusC $C_{\text {RTP }}$ [USD] & - & - & 89.8878 \\
\hline
\end{tabular}

\section{References}

[1] Granovetter M, Mcguire P. The making of an industry: electricity in the United States. Sociol Rev 1998;46(S1):147-73.

[2] Stadler M, Cardoso G, Mashayekh S, Forget T, DeForest N, Agarwal A, et al. Value streams in microgrids: a literature review. Appl Energy 2016;162:980-9.

[3] Schwaegerl C, Tao L. The microgrids concept. In: Chatzēargyriu N, editor. Microgrids: architectures and control. Chichester, West Sussex, UK: Wiley; 2014. p. $1-24$.

[4] Fridgen G, Gründler A, Rusic M. Energy cooperatives as an application of microgrids: multi-criteria investment decision support. 36th intern conf inform syst (ICIS). 2015; 2015.

[5] Hossain E, Kabalci E, Bayindir R, Perez R. Microgrid testbeds around the world: state of art. Energy Convers Manage 2014;86:132-53.

[6] Kariniotakis G, Dimeas A, van Overbeeke F. Pilot sites: success stories and learnt lessons. In: Chatzēargyriu N, editor. Microgrids: architectures and control. Chichester, West Sussex, UK: Wiley; 2014. p. 206-74.

[7] Mariam L, Basu M, Conlon MF. Microgrid: architecture, policy and future trends. Renew Sustain Energy Rev 2016;64:477-89.

[8] Martin-Martínez F, Sánchez-Miralles A, Rivier M. A literature review of microgrids: a functional layer based classification. Renew Sustain Energy Rev 2016;62:1133-53.

[9] Nelson T, McNeill J. Role of utility and pricing in the transition. In: Sioshansi FP, editor. Future of utilities - utilities of the future: how technological innovations in distributed energy resources will reshape the electric power sector. San Diego, California: Elsevier; 2016. p. 109-28.

[10] Seeto D, Woo CK, Horowitz I. Time-of-use rates vs. Hopkinson tariffs redux: an analysis of the choice of rate structures in a regulated electricity distribution company. Energy Econ 1997;19(2):169-85.

[11] Eid C, Reneses Guillén J, Frías Marín P, Hakvoort R. The economic effect of electricity net-metering with solar PV: consequences for network cost recovery, cross subsidies and policy objectives. Energy Pol 2014;75:244-54.

[12] Methenitis G, Kaisers M, La Poutré H. Incentivizing intelligent customer behavior in smart-grids: a risk-sharing tariff \& optimal strategies. Proceedings 25th intern joint conf artif intel (IJCAI-16). 2016; 2016.

[13] Lo Prete C, Hobbs BF. A cooperative game theoretic analysis of incentives for microgrids in regulated electricity markets. Appl Energy 2016;169:524-41.

[14] Rieger A, Thummert R, Fridgen G, Kahlen M, Ketter W. Estimating the benefits of cooperation in a residential microgrid: a data-driven approach. Appl Energy 2016;180:130-41.

[15] Ketter W, Collins J, Reddy P. Power TAC: a competitive economic simulation of the smart grid. Energy Econ 2013;39:262-70.

[16] Woo CK, Sreedharan P, Hargreaves J, Kahrl F, Wang J, Horowitz I. A review of electricity product differentiation. Appl Energy 2014;114:262-72.

[17] Ketter W, Peters M, Collins J, Gupta A. A multiagent competitive gaming platform to address societal challenges. Manage Inform Syst Quart 2016;40(2):447-60.

[18] Hanna R, Ghonima M, Kleissl J, Tynan G, Victor DG. Evaluating business models for microgrids: interactions of technology and policy. Energy Pol 2017;103:47-61.

[19] Sioshansi R. Retail electricity tariff and mechanism design to incentivize distributed renewable generation. Energy Pol 2016;95:498-508.

[20] Comello S, Reichelstein S. Cost competitiveness of residential solar PV: the impact of net metering restrictions. Renew Sustain Energy Rev 2016. http://dx.doi.org/10. 1016/j.rser.2016.10.050. [in press].

[21] Speidel S, Bräunl T. Leaving the grid-the effect of combining home energy storage with renewable energy generation. Renew Sustain Energy Rev 2016;60:1213-24.

[22] Atia R, Yamada N. Sizing and analysis of renewable energy and battery systems in residential microgrids. IEEE Trans Smart Grid 2016;7(3):1204-13.

[23] Zheng M, Meinrenken CJ, Lackner KS. Smart households: dispatch strategies and economic analysis of distributed energy storage for residential peak shaving. Appl Energy 2015;147:246-57.

[24] Li X, Wen J, Malkawi A. An operation optimization and decision framework for a building cluster with distributed energy systems. Appl Energy 2016;178:98-109.

[25] Zhang Di, Shah N, Papageorgiou LG. Efficient energy consumption and operation management in a smart building with microgrid. Energy Convers Mgmt 2013;74:209-22.

[26] Sreedharan P, Farbes J, Cutter E, Woo CK, Wang J. Microgrid and renewable generation integration: University of California, San Diego. Appl Energy 2016;169:709-20.

[27] Firestone R, Magnus Maribu K, Marnay C. The value of distributed generation under different tariff structures. Report number: LBNL-60589; 2006.

[28] Schreiber M, Wainstein ME, Hochloff P, Dargaville R. Flexible electricity tariffs: power and energy price signals designed for a smarter grid. Energy 2015;93:2568-81.

[29] Pecan Street Inc. Pecan Street Dataport. Available from: < https://dataport. pecanstreet.org $>$ [accessed Feb 2017].

[30] Bortolini M, Gamberi M, Graziani A, Manzini R, Pilati F. Performance and viability analysis of small wind turbines in the European Union. Renew Energy 2014;62:629-39.

[31] Tesla, Inc. Powerwall 2 technical specs. Available from: < www.tesla.com/ powerwall $>$ [accessed Feb 2017].

[32] Stadler M, Groissböck M, Cardoso G, Marnay C. Optimizing distributed energy resources and building retrofits with the strategic DER-CAModel. Appl Energy 2014;132:557-67.

[33] Yamamoto Y. Pricing electricity from residential photovoltaic systems: a comparison of feed-in tariffs, net metering, and net purchase and sale. Sol Energy 2012;86(9):2678-85.

[34] Couture T, Gagnon Y. An analysis of feed-in tariff remuneration models: Implications for renewable energy investment. Energy Pol 2010;38(2):955-65.

[35] Darghouth NR, Wiser RH, Barbose G, Mills AD. Net metering and market feedback loops: exploring the impact of retail rate design on distributed PV deployment. App. Energy 2016;162:713-22.

[36] Watts D, Valdés MF, Jara D, Watson A. Potential residential PV development in Chile: the effect of Net Metering and Net Billing schemes for grid-connected PV systems. Renew Sustain Energy Rev 2015;41:1037-51.

[37] Simshauser P. Distribution network prices and solar PV: resolving rate instability and wealth transfers through demand tariffs. Energy Econ 2016;54:108-22.

[38] Paterakis NG, Erdinç O, Catalão JP. An overview of demand response: key-elements and international experience. Renew Sustain Energy Rev 2017;69:871-91.

[39] Hu Z, J-h Kim, Wang J, Byrne J. Review of dynamic pricing programs in the U.S. and Europe: Status quo and policy recommendations. Renew Sustain Energy Rev 2015;42:743-51.

[40] Consolidated Edison Company of New York, Inc. Schedule for PASNY delivery service, P.S.C. no. 12 - Electricity. Available from: < goo.gl/HjnK5Q > [accessed Feb 2017]. 
[41] Hoppmann J, Volland J, Schmidt TS, Hoffmann VH. The economic viability of battery storage for residential solar photovoltaic systems - a review and a simulation model. Renew Sustain Energy Rev 2014;39:1101-18.

[42] Electric Reliability Council of Texas. 2015 Austin load zone real-time settlement point prices'. Available from: < www.ercot.com/mktinfo/prices > [accessed Feb 2017].

[43] Austin Energy. Austin Energy's tariff package: 2015 cost of service study and proposal to change base electric rates; 2016 .

[44] Gottwalt S, Ketter W, Block C, Collins J, Weinhardt C. Demand side management-a simulation of household behavior under variable prices. Energy Pol 2011;39(12):8163-74.

[45] Di Giorgio A, Pimpinella L. An event driven smart home controller enabling consumer economic saving and automated demand side management. Appl Energy 2012;96:92-103.

[46] Di Giorgio A, Liberati F. Near real time load shifting control for residential electricity prosumers under designed and market indexed pricing models. Appl Energy 2014;128:119-32.

[47] Stamminger R, Broil G, Pakula C, Jungbecker H, Braun M, Rüdenauer I, et al. Synergy potential of smart appliances. Report of the Smart-A project; 2008.

[48] Crespo Del Granado P, Pang Z, Wallace SW. Synergy of smart grids and hybrid distributed generation on the value of energy storage. Appl Energy 2016;170:476-88.

[49] Khalilpour KR, Vassallo A. Technoeconomic parametric analysis of PV-battery systems. Renew Energy 2016;97:757-68.

[50] Rodrigues S, Faria F, Ivaki AR, Cafôfo N, Chen X, Mata-Lima H, et al. Tesla Powerwall: analysis of its use in Portugal and United States. Int J Power Energy Syst
2016;36(1).

[51] Truong C, Naumann M, Karl R, Müller M, Jossen A, Hesse H. Economics of residential photovoltaic battery systems in Germany: the case of Tesla's Powerwall. Batteries 2016;2(2):14.

[52] Pecan Street Inc. Pecan Street smart grid demonstration program: final technology performance report; 2015.

[53] Rodríguez Ortega MP, Pérez-Arriaga JI, Abbad JR, González JP. Distribution network tariffs: a closed question? Energy Pol 2008;36(5):1712-25.

[54] Khan AR, Mahmood A, Safdar A, Khan ZA, Khan NA. Load forecasting, dynamic pricing and DSM in smart grid: a review. Renew Sustain Energy Rev 2016;54:1311-22.

[55] Fridgen G, Häfner L, König C, Sachs T. Providing utility to utilities: the value of information systems enabled flexibility in electricity consumption. J Assoc Inform Syst 2016;17(8):537-63.

[56] Gu W, Wu Z, Bo R, Liu W, Zhou G, Chen W, et al. Modeling, planning and optimal energy management of combined cooling, heating and power microgrid: a review. Int J Electric Power Energy Syst 2014;54:26-37.

[57] Prüggler N. Economic potential of demand response at household level - are Central-European market conditions sufficient? Energy Pol 2013;60:487-98.

[58] Qian LP, Zhang YJA, Huang J, Wu Y. Demand response management via real-time electricity price control in smart grids. IEEE J Select Areas Commun 2013;31(7):1268-80

[59] Amini MH, Frye J, Ilic MD, Karabasoglu O. Smart residential energy scheduling utilizing two stage Mixed Integer Linear Programming. In: 2015 North Amer power symp. p. 1-6. 